\title{
Friction in Automotive Engines
}

\author{
H. Allmaier, C. Priestner, D.E. Sander and F.M. Reich
}

Additional information is available at the end of the chapter

http://dx.doi.org/10.5772/51568

\section{Introduction}

The current situation of the automotive industry is a challenging one. On one hand, the ongoing trend to more luxury cars brings more and more benefits to the customer and is certainly also an important selling point. The same applies to the increased safety levels modern cars have to provide. However, both of these benefits come with a severe inherent drawback and that is extra weight and, consequently, higher fuel consumption. On the other hand, increased fuel consumption is not only a disadvantage due to the ever rising fuel costs and the corresponding customer demand for more efficient cars. Due to the corresponding greenhouse gas emissions it is also in the focus of the legislation in many countries. Commonly road transport is estimated [13, 15] to cause about $75-89 \%$ of the total $\mathrm{CO}_{2}$ emissions within the world's transportation sector and for about $20 \%$ of the global primary energy consumption [12]. These values do not stay constant; in the time from 1990 to 2005 , the required energy for transportation increased by $37 \%$ [11] and further increases are expected due to the evolving markets in the developing countries. As industrial emissions decrease, the rising energy demand in the transport sector is expected to be the major problem to achieve a significant greenhouse gas reduction [26]. Consequently, about all major automotive markets introduce increasingly strict emission limits like the national fuel economy program implemented in the CAFE regulations in the US, the EURO regulation in the European Union or the FES in China.

In particular, the European union introduced a limit for the average $\mathrm{CO}_{2}$ emissions for all cars to be available on the European market of $130 \mathrm{~g} \mathrm{CO}_{2} / \mathrm{km}$ by $2015^{1}$. Further, a long term target of $95 \mathrm{~g} \mathrm{CO}_{2} / \mathrm{km}$ was specified for 2020 [6]. To put this into perspective, the average fleet consumption in 2007 was $158 \mathrm{~g} \mathrm{CO}_{2} / \mathrm{km}$ and it had taken already about 10 years to get down to this value from the $180 \mathrm{~g} \mathrm{CO}_{2} / \mathrm{km}$ that were achieved in 1998 . Now a larger reduction is required in less time. The required reduction of emissions brings also a direct benefit for the customer as the fuel consumption is lowered. It is estimated [11] that the

\footnotetext{
${ }^{1}$ The limit applies to the average fleet consumption of every car manufacturer, calculated by averaging the fuel consumption of all offered car models and weighted by the number of sold units of the specific models.
} 
average car consumes every year about 169 litres of fuel only to overcome mechanical friction in the powertrain. There exist several efficient measures to lower the emissions, notably to decrease the weight of the car itself to reduce the energy needed for acceleration, to optimize the combustion process and, of course, to reduce all inherent power losses like the tyre rolling resistance, aerodynamic drag and mechanical losses of the powertrain (combination of engine and transmission) itself. These measures are, however, not straightforward as some have drawbacks or are even in conflict with each other. For example, smaller cars that offer reduced weight have commonly worse aerodynamic drag as their shape is more cube-like for practical reasons [8]. Also, a reduction in aerodynamic drag brings only a small benefit in the urban traffic due to the low cruising speeds involved. A reduction of tyre rolling resistance is hard to achieve without reduced performance in other areas like handling and traction [10]. Weight reduction is expensive as more and more lightweight and expensive materials have to be used, some of which also require a lot of energy in the production process. In addition, it was shown [8] that there is no positive synergy effect: the combination of several of the mentioned measures reduces their individual efficiency, such that their combination brings less benefit than anticipated.

In contrast, making the powertrain more efficient yields a proportional reduction in $\mathrm{CO}_{2}$ emissions [8]. For low load operating conditions of Diesel engines friction reduction is even the prime measure to further decrease fuel consumption [16]. While currently a lot of work is done in the automotive industry to reduce the losses caused by the auxiliary systems like the oil or coolant pump, it was shown at hand of a specific engine that the potential for friction reduction in the ICE itself is of comparable magnitude [16].

\section{Sources of friction in ICEs}

Before any efficient measures to reduce friction in engines can take place, the main friction sources need to be known. At the Virtual Vehicle Competence Center, we use our friction test-rig as shown in Fig. 1 to investigate the sources of friction for a typical four cylinder gasoline engine; exemplary results for this engine are shown in Fig. 2.

The chart confirms the commonly propagated main sources of friction: the piston-liner contact is the cause for about $60 \%$ of the total mechanical losses, while the journal bearings in the crank train (main and big end bearings) contribute about 30\%. Finally, the valve train generally represents the third main source of friction and typically causes losses that equal roughly about the half of the power losses in the journal bearings [19] (not included in Fig. 2).

While not only the amount of friction is different between the various sources, also the character of friction, namely the lubrication regime itself, is also notably different. While the journal bearings are generally full film lubricated with no metal metal contact occurring under normal operating conditions, parts of the piston assembly experience metal-metal contact under high load. In particular, the top ring of the piston has metal-metal contact every time it passes the top dead center as no oil can reach this point. This is of particular severity as at firing top dead center a large force acts on the top ring and presses it onto the cylinder liner during the downward motion of the piston. Besides the fact that the piston assembly has generally been the largest contributor to the total mechanical losses, it has several other important functions. Amongst others it has to seal the combustion chamber in both directions, 


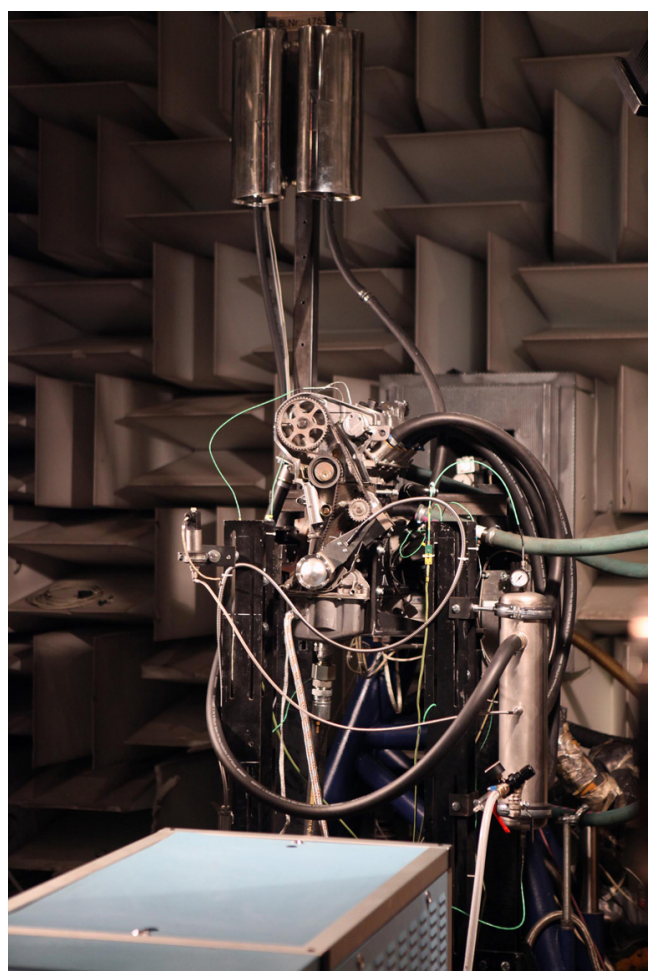

Figure 1. Friction measurement test-rig FRIDA during build-up at the Virtual Vehicle Competence Center. It is shown being applied to an inline four cylinder gasoline engine with 1.8 litres total displacement.

both to avoid so-called blow-by gases from entering the engine housing, as well as to control the amount of lubricant being left on the cylinder liner. The blow-by gases have to be controlled as these both cause a loss in convertible energy by decreasing the available cylinder pressure as well as have a negative deteriorating impact on the lubricant properties. The oil being left on the cylinder liner needs to be carefully controlled as well: while a certain amount of oil is necessary to provide sufficient lubrication for the piston rings, it is burned during combustion. Burning too much oil needs to be avoided not only for practical reasons as it needs to be replaced (increased service demand), but also as some of its contents are problematic for the exhaust aftertreatment systems.

Additionally, depending on operating condition unstable behaviour of the piston rings may occur [27] like ring flutter (rapid oscillating movement of the piston ring in its groove) or ring collapse (inward forces on the ring exceed the ring tension), which needs to be avoided in practical designs. To summarize, the piston assembly has to fulfil many functions. For focusing solely on friction it is, therefore, not used in this work. In the following, the second largest contributor to the total losses in engines, namely the journal bearings, are discussed. 


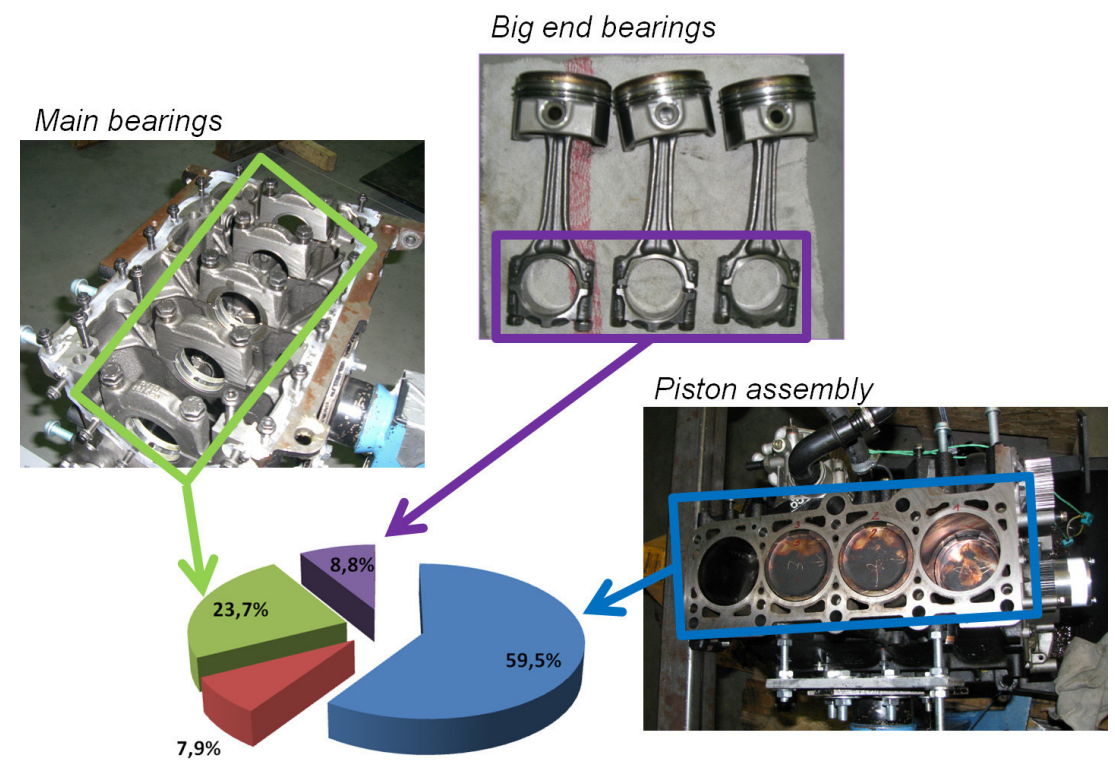

Figure 2. Examplary relative contributions to the total friction losses in an inline 4 cylinder gasoline engine with 1.8 litre total displacement. Shown in blue is the contribution of the piston assembly, in green the contribution of the main bearings, in violet the amount caused by the big end bearings and, finally, the red part shows the contribution of all other components like seals etc. The valve train is not included in these results, also all auxiliary systems (oil pump etc.) are removed.

\section{Calculating power losses due to friction in the journal bearings}

In contrast to the piston assembly that has to perform a large number of tasks which are partially conflicting as previously discussed, journal bearings are due to their apparent simplicity particularly suited to discuss the sources of friction.

Journal bearings are from their appearance simple devices; generally formed from sheet metal they are typically low cost parts, with one bearing shell costing a few single Euros or less. However, this simplicity is misleading, as in fact they have to combine a wide range of properties which impose conflicting requirements on the material properties to be used. While the bearing material should be hard to resist wear, in the engine it shall also embed well debris particles that originate from wear or even from the original manufacturing process of the engine housing. For the latter property softer materials are beneficial which conflicts with the requirement to resist wear. These requirements led to the development of multi layer bearings, where each layer is optimized for a specific task.

In the following a method is described that accounts for many of the essential physical processes that occur in journal bearings during operation and allows to accurately predict the power losses due to friction. The method is developed while discussing these processes and its validity is shown by numerous comparisons to experimental data. 
While the focus in the following is on monograde oils as they are used in large stationary engines, the results also apply correspondingly to multigrade oils with their shear rate dependence taken into account.

In the following the results from a number of works are presented in a shortened form with a particular focus on the results and their context. All details can be found in the original works $[1-3,24,25]$.

\subsection{An isothermal EHD approach}

In an ICE, journal bearings are generally exposed to different operation conditions in terms of load, speed and temperature. As depicted in Fig. 3, depending on relative speed, load and viscosity the operating conditions reflected as friction coefficient may range from purely hydrodynamic lubrication with a sufficiently thick oil film to mixed or even boundary lubrication with severe amounts of metal to metal contact.

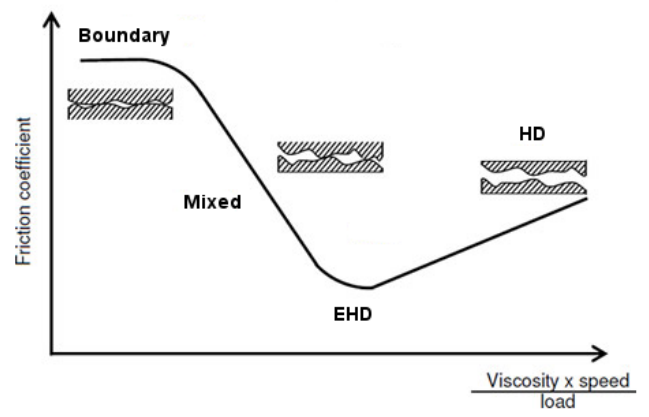

Figure 3. The Stribeck-plot showing the different regimes of lubrication: hydrodynamic (HD), elastohydrodynamic (EHD), mixed and boundary lubrication

To calculate the movement of the journal under the applied load and the corresponding pressure distribution within the oil film an average Reynolds equation is used, that takes into account the roughness of the adjacent surfaces. When the typical minimum oil film thickness is of comparable magnitude to the surface roughness, the lubricating fluid flow is also affected by the surface asperities and their orientation. To account for this modification of the fluid flow we use the average Reynolds equation as developed by Patir and Cheng [21, 22], which can be written in a bearing shell fixed coordinate system as

$$
\begin{aligned}
& -\frac{\partial}{\partial x}\left(\theta \phi_{x} \frac{h^{3}}{12 \eta_{p}} \frac{\partial p}{\partial x}\right)-\frac{\partial}{\partial z}\left(\theta \phi_{z} \frac{h^{3}}{12 \eta_{p}} \frac{\partial p}{\partial z}\right)+ \\
& +\frac{\partial}{\partial x}\left(\theta\left(\bar{h}+\sigma_{s} \phi_{s}\right) \frac{U}{2}\right)+\frac{\partial}{\partial t}(\theta \bar{h})=0,
\end{aligned}
$$

where $x, z$ denote the circumferential and axial directions, $\theta$ the oil filling factor and $h, \bar{h}$ the nominal and average oil film thickness, respectively. Further, $U$ denotes the journal 
circumferential speed, $\eta_{p}$ the pressure dependent oil viscosity and $\sigma_{s}$ the combined (root mean square) surface roughness. $\phi_{x}, \phi_{z}, \phi_{s}$ represent the flow factors that actually take into account the influence of the surface roughness.

To describe mixed lubrication another process needs to be taken into account, namely the load carried by the surface asperities when metal-metal contact occurs.

The corresponding quantity is the asperity contact pressure $p_{\mathrm{a}}$ and together with the area experiencing metal-metal contact, $A_{\mathrm{a}}$, and the boundary friction coefficient $\mu_{\text {Bound }}$ these yield the friction force $R_{\text {Bound }}$ caused by asperity contact,

$$
R_{\text {Bound }}=\mu_{\text {Bound }} \cdot p_{\mathrm{a}} \cdot A_{\mathrm{a}} \text {. }
$$

To describe the metal-metal contact we use the Greenwood and Tripp approach [9], that is shortly outlined in the following.

The theory of Greenwood and Tripp is based on the contact of two nominally flat, random rough surfaces. The asperity contact pressure $p_{\mathrm{a}}$ is the product of the elastic factor $K$ with a form function $F_{\frac{5}{2}}\left(H_{S}\right)$,

$$
p_{\mathrm{a}}=K E^{*} F_{\frac{5}{2}}\left(H_{S}\right)
$$

where $H_{S}$ is a dimensionless clearance parameter, defined as $H_{S}=\frac{h-\bar{\delta}_{s}}{\sigma_{s}}$, with $\sigma_{S}$ being the combined asperity summit roughness, which is calculated according to

$$
\sigma_{s}=\sqrt{\sigma_{S, J}^{2}+\sigma_{s, S}^{2}}
$$

and $\bar{\delta}_{s}$ being the combined mean summit height, $\bar{\delta}_{S}=\bar{\delta}_{s, J}+\bar{\delta}_{s, S}$, where the additional subscript $J$ and $S$ denotes the corresponding quantities of the journal and the bearing shell, respectively. Further, $E^{*}$ denotes the composite elastic modulus, $E^{*}=\left(\frac{1-v_{1}^{2}}{E_{1}}+\frac{1-v_{2}^{2}}{E_{2}}\right)^{-1}$, where $v_{i}$ and $E_{i}$ are the Poisson ratio and Young's modulus of the adjacent surfaces, respectively. The form function is defined as

$$
\begin{aligned}
F_{\frac{5}{2}}\left(H_{S}\right) & =4.4086 \cdot 10^{-5}\left(4-H_{S}\right)^{6.804} \text { for } H_{S}<4 \\
& =0 \text { for } H_{S} \geq 4,
\end{aligned}
$$

which shows that friction due to asperity contact sets in only for $H_{S}<4$ and further sensibly depends on the minimum oil film thickness as this quantity enters Eqn. 4 with almost 7 th power.

For the calculation of the Greenwood/Tripp parameters a 2D-profilometer trace was used that was performed on an run-in part of the bearing shell along the axial direction.

Modern engine oils include friction modifying additives like zinc dialkyl dithiophosphate (ZDTP) or Molybdenum based compounds to lower friction and wear in case metal-metal contact occurs. For the Greenwood and Tripp contact model we employed in the following a boundary friction coefficient of $\mu_{\text {Bound }}=0.02$.

The different contributions to friction, as listed in Eqs. (1) and (3), are generally not independent from eachother. A reduction in lubricant viscosity, while decreasing 
hydrodynamic losses, may cause - depending on the load - an overly increase in asperity contact as the oil film thickness enters Eq. (4) with almost 7th power.

\subsubsection{Testing Method}
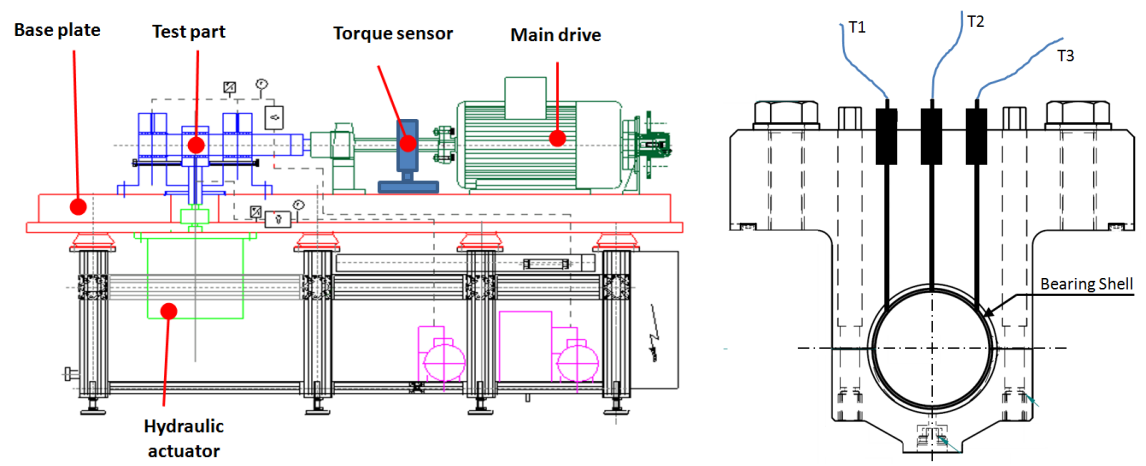

Figure 4. left: schematic drawing of the journal bearing test rig LP06: test part denotes the location of the test bearing, torque sensor the HBM T10F sensor used for friction moment measurement. Right: Drawing of the test con rod with test bearing showing the location of the temperatures sensors: T2 sits in the center at $0^{\circ}$ circumferential angle, with $\mathrm{T} 1$ and $\mathrm{T} 3$ at $\pm 45^{\circ}$ circumferential angle, respectively.

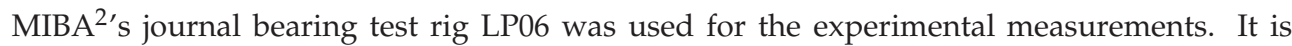
sketched in Fig. 4 and consists of a heavy, elastically mounted base plate which carries the two support blocks, the test con rod with the hydraulic actuator and the driveshaft attached to the electric drive mechanism. The hydraulic actuator applies the load along the vertical direction, which is consequently defined as $0^{\circ}$ circumferential angle.

The friction torques arising from all three journal bearings were measured at the driveshaft; for the comparisons load cycle averaged values of the friction moment (the load cycle is depicted in Fig. 5) are used.

The LP06 is equipped with a number of temperature sensors to capture the occurring temperatures at various points of the test rig; to this task temperature is measured by using thermocouple elements of type $\mathrm{K}$ that have an accuracy of $\pm 1^{\circ} \mathrm{C}$. Besides two temperatures in the con rod and the oil outflow temperature, the bearing shell temperatures of the test and support bearings are measured at three different points at the back of each corresponding bearing shell. As shown in Fig. 4, two of these temperature sensors are located at $\pm 45^{\circ}$ circumferential angle from the vertical axis and the third in the middle at $0^{\circ}$ circumferential angle.

For the bearing tests following conditions were maintained: for test- and support-bearings steel-supported leaded bronce trimetal bearings with a sputter overlay were employed; for each test-run new bearings with an inner diameter of $76 \mathrm{~mm}$ and a width of $34 \mathrm{~mm}$ were used and mounted into the test rig with a nominal clearance of $0.04 \mathrm{~mm}(1 \% 00$ relative clearance). A hydraulic attenuator applied the transient loads with the corresponding peak loads of either

\footnotetext{
${ }^{2}$ MIBA Bearing Group, Dr.-Mitterbauer-Str. 34663 Laakirchen, Austria
} 


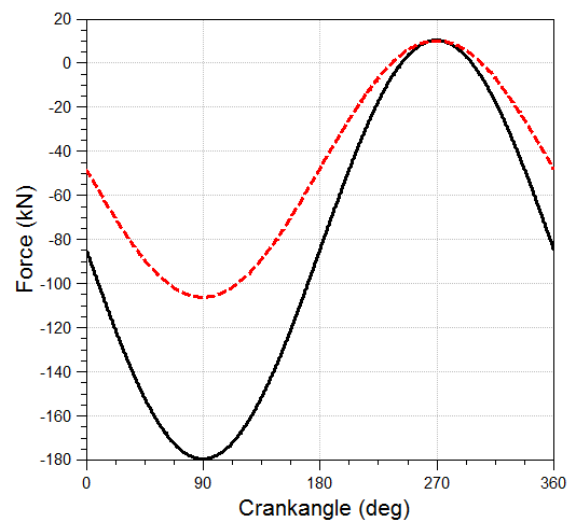

Figure 5. Plot of the loads applied to the test bearing: at a frequency of $50 \mathrm{~Hz}$ a sinusoidal load is applied along the vertical direction with a preload of $-10 \mathrm{kN}$ and a peak load of either $180 \mathrm{kN}$ for the $70 \mathrm{MPa}$ load case (shown as solid black line) or a peak load of $106 \mathrm{kN}$ for the $41 \mathrm{MPa}$ load case (red dashed line).

$41 \mathrm{MPa}, 54 \mathrm{MPa}, 70 \mathrm{MPa}$ or $76 \mathrm{MPa}$. For a convenient comparison of the results to other works the peak load is expressed in MPa to account for the involved bearing dimensions. This is conducted by dividing the load force by the projected bearing area (product of bearing width and bearing diameter). Therefore, the peak loads of $106 \mathrm{kN}$ and $180 \mathrm{kN}$ correspond to $41 \mathrm{MPa}$ or $70 \mathrm{MPa}$, respectively, for the present bearing dimensions (see also Fig. 5). In the following, the corresponding peak loads are used to distinguish between the different transient load cases.

The different oils were preconditioned to $80 \pm 5^{\circ} \mathrm{C}$ inflow temperature. After the test-run the wear at several points in the journal bearings was measured and the so obtained wear profiles were included in the simulation model.

\subsubsection{Simulation}

For the simulation a model of the LP06 was setup within an elastic multi-body dynamics solver (AVL-Excite Powerunit ${ }^{3}$ ). The simulation model consists of the test con rod including the test bearing, the two support-blocks with journal bearings and the shaft running freely, but supported by the adjacent bearings. All structure parts are modeled as dynamically condensed finite element (FE)-structures.

The three journal bearings, $76 \mathrm{~mm}$ in diameter and $34 \mathrm{~mm}$ width, are represented as EHD or TEHD-joints, respectively.

To obtain realistic dynamic lubricant viscosities for the calculations, the viscosities and densities of fresh SAE10/SAE20/SAE30 and SAE40 monograde oils were measured at different temperatures in the OMV-laboratory ${ }^{4}$. To obtain a pressure dependent oil-model for the simulation, the pressure dependency was impressed onto the measured viscosities by

\footnotetext{
${ }^{3}$ AVL List GmbH, Advanced Simulation Technology, Hans-List-Platz 1, 8020 Graz, Austria

${ }^{4}$ OMV Refining \& Marketing GmbH, Uferstrasse 8, 1220 Wien, Austria
} 
applying the well known Barus-equation [5] with the coefficients from [5]. The so resulting dynamic viscosities correspond qualitatively to experimental data [4]. Further, a dependence on hydrodynamic pressure was impressed onto the lubricant density following the data found experimentally by Bair et al. [4].

The dynamic viscosities and oil-densities are shown for the SAE10, SAE20, SAE30 and SAE40-oils in Fig. 6. As can be seen in these figures, a hydrodynamic pressure of about $60 \mathrm{MPa}$ leads to roughly a doubling of the dynamic viscosity and, therefore, to a strong increase in the related hydrodynamic losses. While for now the presented calculations do not take into account the local temperatures of the lubricant in the bearing itself, the strong variation of the physical properties of the oil with temperature show the importance of defining a representative global lubricant temperature as discussed in the next subsection.

\subsubsection{Deriving the oil-temperature}

A plausible choice of this temperature is important as it directly relates to the lubricant viscosity and consequently acts on the minimum oil film thickness and the amount of asperity contact.

For the presented pressure dependent lubricant model, the calculation of the global oil temperature is straightforward: as the oil viscosity increases strongly for hydrodynamic pressures exceeding about $1 \mathrm{MPa}$, the hydrodynamic losses in the lubricant are expected to be dominated by this thickening in the high-load area of the bearing. This argument is also supported later on by the simulation results which predict hydrodynamic pressures of up to $120 \mathrm{MPa}$ in large areas in the bearing. Following this line of argument, the global oil temperature is estimated from the measured bearing back temperatures, by averaging the test and support bearing back temperatures that are located at $\pm 45^{\circ}$ circumferential angle $\left(T_{1}, T_{3}\right)$ of the one in the high load zone, $T_{2}$, as shown in Fig. 4 . Although the so obtained temperature is rather high in comparison to the oil inflow temperature it is expected to realistically estimate the hydrodynamic losses as well as the amount of asperity contact, as this temperature describes closely the oil viscosity in the high load zone.

The such calculated oil-temperatures are depicted in Table 1 for the load cases studied in the following and for simplicity the same oil temperature is used for all three bearings.

\subsubsection{Surface profiles}

For a sufficiently accurate calculation of the asperity contact, it is necessary to use realistic surface shapes in the simulation [24]. Ideal geometric shapes are not suitable for this task, as due to elastic deformation of the structure under load, the bearing pin would express overly large pressures on the outermost nodes of the bearing shell, leading to unrealistically high amounts of asperity contact. This in turn causes an overestimation of the friction moment.

Therefore, the bearing shell surface of the test bearing was measured for wear at several points after the test runs; the procedure is discussed in more detail in [24]. The wear data obtained from the two performed SAE10-oil test-runs were averaged and symmetrized as we do not include misalignments due to imperfect mounting in the simulation. The such obtained wear 


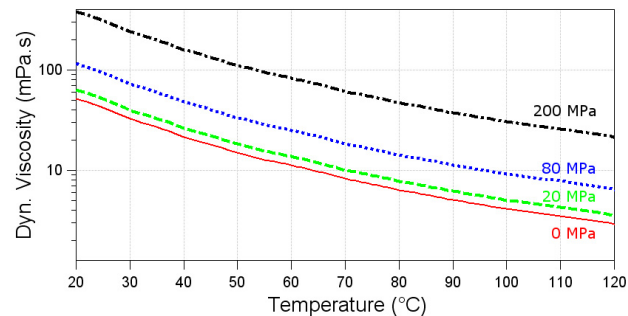

(a)

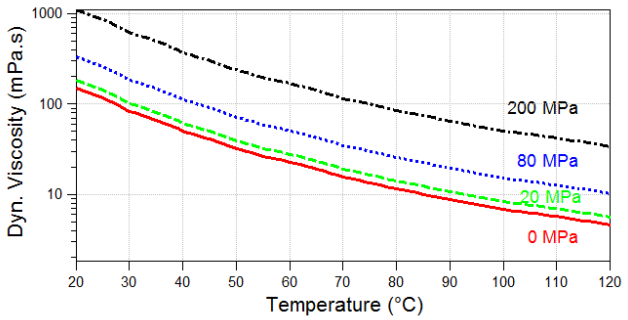

(b)

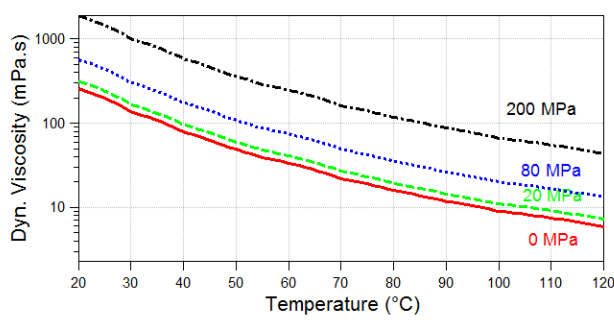

(c)

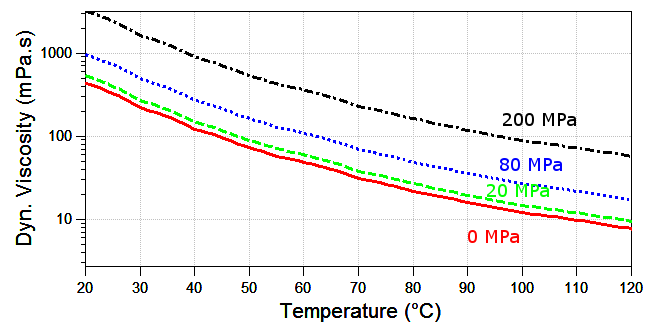

(d)

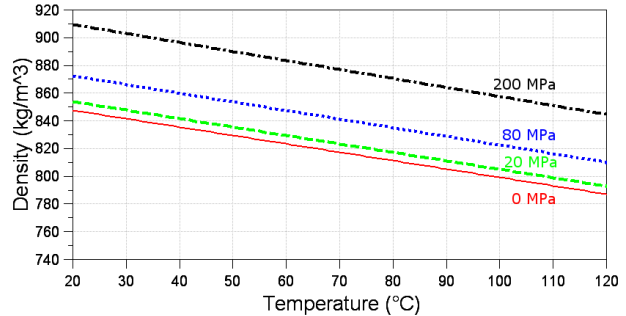

(e)

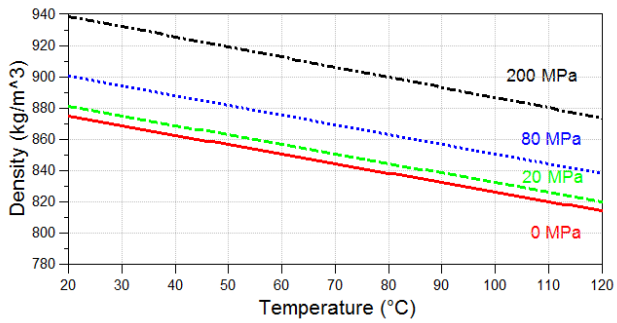

(f)

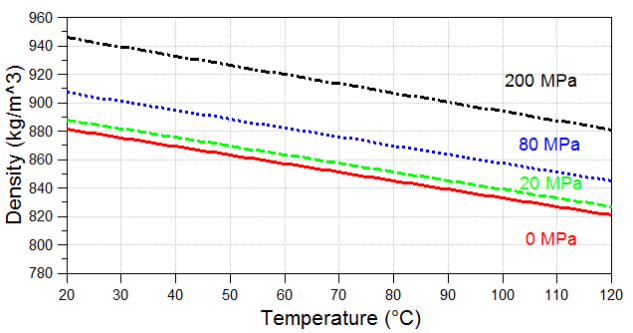

(g)

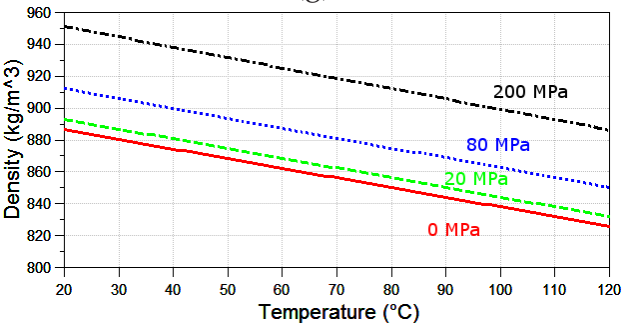

(h)

Figure 6. Dynamic viscosities (a-d) and densities (e-h) of the lubricants as described by the oil model for SAE10/SAE20/SAE30/SAE40 (top to bottom): the solid red lines denote the corresponding physical property at $0 \mathrm{~Pa}$, the green dashed lines at $20 \mathrm{MPa}$, the blue dotted lines for $80 \mathrm{MPa}$ and the black dash-dotted lines for $200 \mathrm{MPa}$. 


\begin{tabular}{|c|c|c|}
\hline SAE10 & $\begin{array}{c}\mathrm{T}_{41 \mathrm{MPa}} \\
{\left[{ }^{\circ} \mathrm{C}\right]}\end{array}$ & $\begin{array}{c}\mathrm{T}_{70 \mathrm{MPa}} \\
{\left[{ }^{\circ} \mathrm{C}\right]}\end{array}$ \\
\hline \hline & 87.4 & 94.6 \\
\hline \hline SAE20 & $\begin{array}{c}\mathrm{T}_{41 \mathrm{MPa}} \\
{\left[{ }^{\circ} \mathrm{C}\right]}\end{array}$ & $\begin{array}{c}\mathrm{T}_{70 \mathrm{MPa}} \\
{\left[{ }^{\circ} \mathrm{C}\right]}\end{array}$ \\
\hline \hline & 89.2 & 96.8 \\
\hline \hline SAE30 & $\begin{array}{c}\mathrm{T}_{41 \mathrm{MPa}} \\
{\left[{ }^{\circ} \mathrm{C}\right]}\end{array}$ & $\begin{array}{c}\mathrm{T}_{70 \mathrm{MPa}} \\
{\left[{ }^{\circ} \mathrm{C}\right]}\end{array}$ \\
\hline \hline & 89.8 & 97.9 \\
\hline SAE40 & $\mathrm{T}_{41 \mathrm{MPa}}$ & $\mathrm{T}_{70 \mathrm{MPa}}$ \\
& {$\left[{ }^{\circ} \mathrm{C}\right]$} & {$\left[{ }^{\circ} \mathrm{C}\right]$} \\
\hline \hline & 91.8 & 99.6 \\
\hline
\end{tabular}

Table 1. Calculated oil-temperatures (see text) for the studied load cases (denoted as subscript) and the different oils.

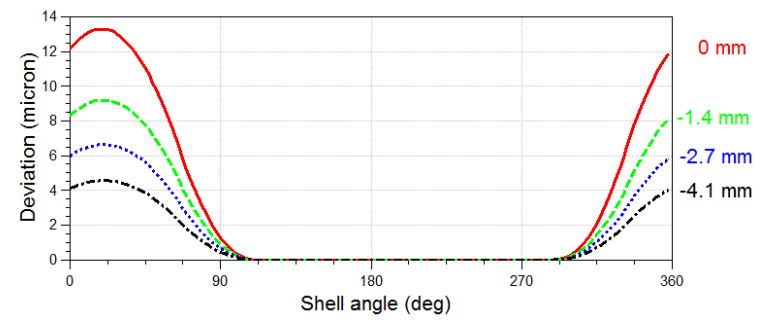

Figure 7. Surface profile used for the test bearing in the simulation, shown as deviation (in $\mu \mathrm{m}$ ) from the nominal geometrical shape of the bearing shell for different axial cuts: the red line denotes the deviation at the outermost bearing nodes, $0 \mathrm{~mm}$ from the shell edges, the green dashed line the deviation $-1.4 \mathrm{~mm}$ from the shell edges, the blue dotted line the deviation $-2.7 \mathrm{~mm}$ from the bearing edges and the black dash-dotted line shows the deviation $-4.1 \mathrm{~mm}$ from the bearing edges. The deviations in the middle of the journal bearing, along axial direction from $-4.1 \mathrm{~mm}$ to $-17 \mathrm{~mm}$ from the bearing edges, stay rather constant and are almost identical to the deviation for $-4.1 \mathrm{~mm}$ away from the bearing edges.

profiles, depicted in Fig. 7, were used for all consequent calculations (all lubricants and loads) as it was found that the results with individual wear profiles prepared for every lubricant caused only negligible differences in comparison to the results obtained with the SAE10-wear profile. Similar wear profiles were used for the support bearings, which, however, are less critical as each of these carries only half of the total load.

\subsubsection{Results}

In the following, the results obtained from simulation are compared to the experimental results. For this task, the results are discussed starting from full fluid film lubrication (purely hydrodynamic losses), as it is the case for SAE40, to working conditions which progress increasingly into mixed lubrication, like it is the case for SAE10, where friction power losses due to metal-metal contact become significant. 
The simulations for the different lubricants were conducted and the calculated friction moments are shown and compared to the experimental values in Fig. 8. The obtained experimental values range from as low as 3 to $8 \mathrm{Nm}$, where the individual average friction torques are measured (with the exception of the 3000rpm cases where only a smaller amount of measurement data is available) with an accuracy of about $0.5 \mathrm{Nm}$ (denoted as black bars in the plot).

Regarding the general trends, the resulting average friction moment scales with the applied load and for a given load, with the journal speed. For a specific load/journal speed case, the friction moment depends significantly on the different lubricant viscosities.

Due to the large number of cases shown in Fig. 8 the focus will be in particular on the results for a journal speed of 2000rpm and two different load cases in the following.

Comparing the results predicted by simulation to the experimental data, we start by looking first at the SAE40 lubricant. From experience it is known that for a load of 41 MPa SAE40 oil provides sufficient lubrication for reliable long term use and, thus, avoids asperity contact. This is confirmed by the results from simulation, as these do not show any asperity contact, see Fig. 9. The same is almost true for the $70 \mathrm{MPa}$ case, although simulation predicts about 0.5 $\mathrm{W}$ power losses due to the metal-metal contact in this case. However, this amount is negligible compared to the total losses of $626 \mathrm{~W}$.

Starting from the purely hydrodynamic case with SAE40 lubrication, excluding one case all results from simulation are within the measurement uncertainty of the experimental results and commonly even closer to the average friction torque. The result calculated for the excluded case is also close to the measurement uncertainty.

Lowering the lubricant viscosity by about $25 \%$ compared to the SAE40 lubricant, one arrives at the cases with lubrication with SAE30. Here, the onset of mixed lubrication occurs for the highest dynamic load of $70 \mathrm{MPa}$ at the lowest journal speed of 2000rpm. For this smaller load, there is still no asperity contact predicted and all losses are caused by the dynamic viscosity of the lubricant. Beginning with this lubricant class the validity of the chosen asperity contact model starts to get tested. While the power losses are still strongly dominated by hydrodynamic losses, the power losses due asperity contact contribute about $1 \%$ (7 W averaged over a full crank cycle) to the total power losses. The corresponding asperity contact pressure (shown in Fig. 10 for all lubricants for the load case of $70 \mathrm{MPa}$ and a journal speed of 2000rpm), however, increases for the SAE30 lubricant to a maximum of $15 \mathrm{MPa}$, which indicates that wear starts to occur in the highly loaded parts of the journal bearing.

However, comparing the results from simulation with the experimental data, the same level of accuracy can be seen in Fig. 8. In fact, the actual predicted value from simulation is generally even closer to the measured averaged value.

Lowering the lubricant viscosity once more to SAE20, the journal bearing experiences more and more mixed lubrication. While metal-metal contact is still absent for a load of $41 \mathrm{MPa}$, it starts to become significant for the $70 \mathrm{MPa}$ load case. In total the losses due to metal-metal contact are still rather low representing only about $4 \%$ of the total power losses for the worst case as shown in Fig. 9. Due to the reduced viscosity in comparison to SAE30-oil, the experimentally observed average friction moments are reduced, however, asperity contact 
(a)

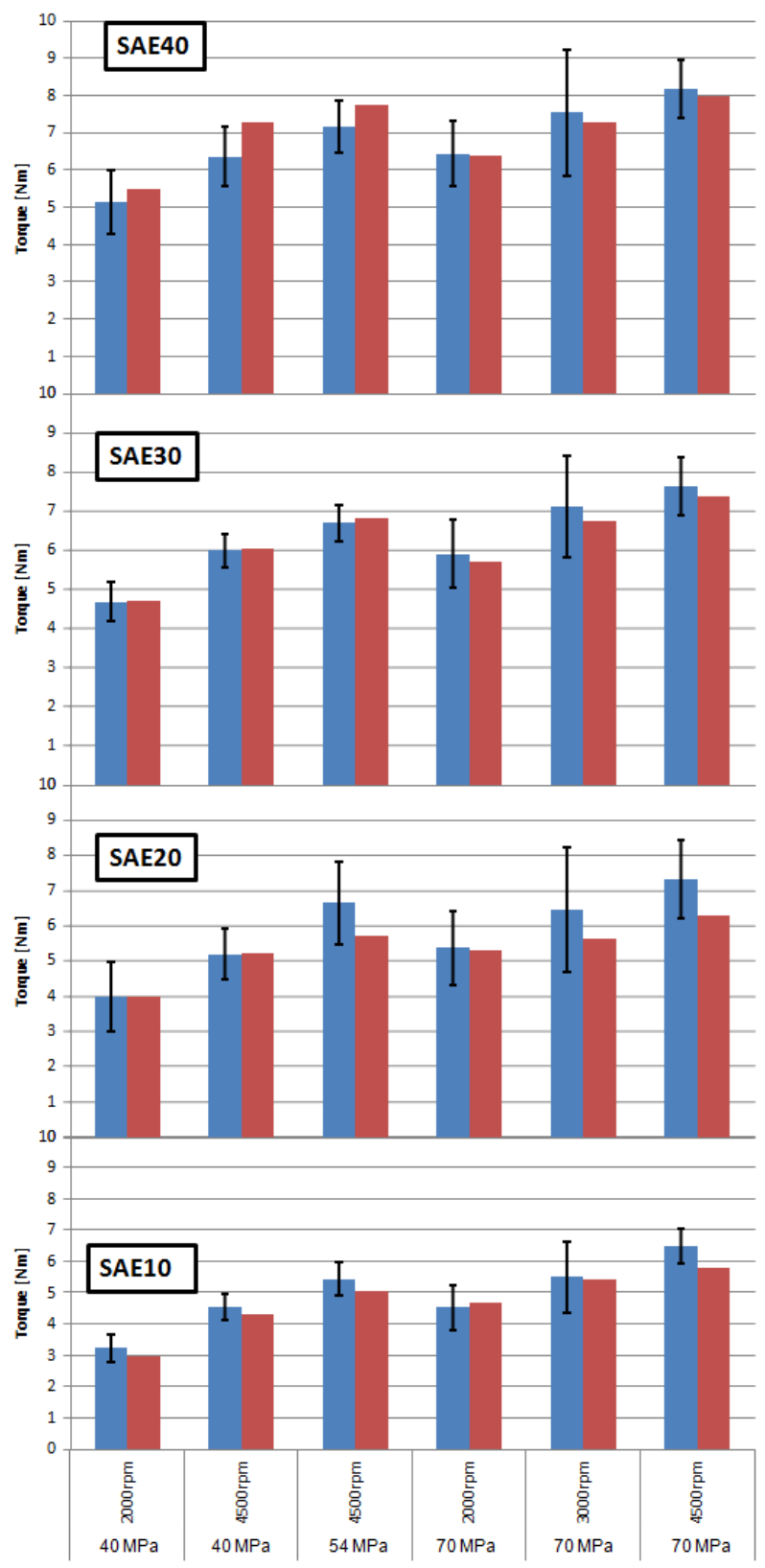

Figure 8. Comparison of the friction torques measured on the test-rig (blue) together with the measurement uncertainty (black bars) with the results from simulation (illustrated in red) for different journal speeds (2000/3000/4500rpm), different dynamic loads (40/54/70 MPa) and different lubricants (SAE40/SAE30/SAE20/SAE10). 


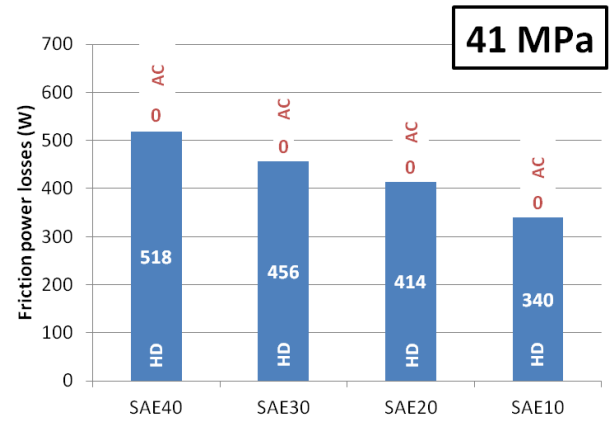

(a)

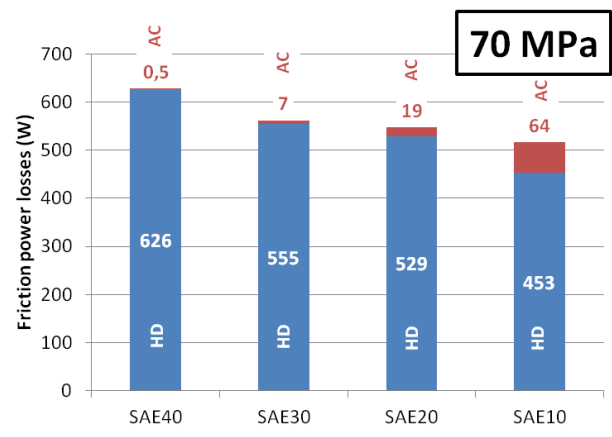

(b)

Figure 9. Comparison of the contributions to the friction power losses in the test bearing for a load of (a) $41 \mathrm{MPa}$ and (b) $70 \mathrm{MPa}$ for 2000rpm journal speed calculated for the different oils: hydrodynamic losses are denoted as HD and losses due to asperity contact are denoted as AC.

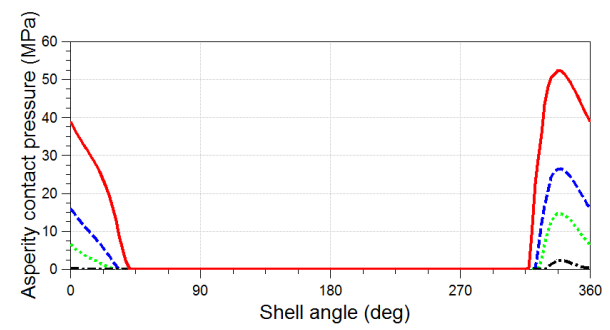

Figure 10. Comparison of the asperity contact pressures occurring at the outermost bearing shell edges for a load of $70 \mathrm{MPa}$ for the different oils: SAE10 denoted as solid red line, SAE20 denoted as dashed blue line, SAE30 and SAE40 shown as green dotted line and as black dash-dotted line, respectively.

begins to reduce the benefit of the decreased hydrodynamic losses. As can be seen from the results, also for this case the prediction accuracy of the presented simulation method lies for all cases studied within the measurement uncertainty of the experimental data.

Finally, arriving at the lowest viscosity lubricant SAE10 this case represents the most severe operating conditions in terms of mixed lubrication that are investigated in this work. For the most severe case of the highest dynamic load of $70 \mathrm{MPa}$ and the lowest journal speed studied of 2000rpm, already about $14 \%$ of the total power losses are caused by metal-metal contact. While the journal bearing might endure these conditions on the test-rig still for a rather long time, the amount of metal-metal contact is much to high to be allowed in real world applications. Significant wear occurs every load cycle which does not stabilize after a run-in period and leads, therefore, to a constant wear of the bearing shell. For the lower load case of $41 \mathrm{MPa}$, simulation still predicts no asperity contact and attributes all friction power losses to the hydrodynamic losses, see Fig. 9.

Finally, the ability of the presented method to predict the existence of metal-metal contact is put to test. For this task, a bearing durability test is investigated. For this test, the operating 
conditions are made even more severe by increasing the dynamic load to a maximum of 76 $\mathrm{MPa}$ at a journal speed of 3000rpm and increasing the oil inflow temperature of the SAE10 lubricant to $110^{\circ} \mathrm{C}$. In comparison to the previous operating conditions with an oil inflow temperature of $80^{\circ} \mathrm{C}$, this temperature increase causes the lubricant viscosity to decrease by more than $50 \%$ (see Fig. 6). These operating conditions lead consequently to bearing shell temperatures exceeding $130^{\circ} \mathrm{C}$. As significant metal-metal contact occurs for these operating conditions, it can be detected by contact voltage measurements. For this measurement, a voltage is applied e.g. in form of a charged capacitor between the journal and the bearing. As the lubricant has only a poor electrical conductivity, the capacitor stays charged and the voltage remains unchanged. When metal-metal occurs, the capacitor can discharge due to the corresponding increased electrical conductivity; this process can be observed as change (decrease) of the voltage.

A comparison of the experimental contact voltage measurement and the predicted metal-metal contact is shown in Fig. 11 together with the applied dynamic load. It can be seen that when the load exceeds a certain threshold, metal-metal contact occurs. When compared to the results from simulation, the onset and the duration of the calculated metal metal contact agrees very well with the measured contact voltage data.

Overall, the presented simulation method appears to describe the actual processes in the journal bearing sufficiently well, as it predicts the friction moment accurately and reliably over a large range of working conditions, which range from purely hydrodynamic to significantly mixed lubrication.

Other important properties related to reliability in lubricated journal bearings are the peak oil film pressure (POFP) and the minimum oil film thickness (MOFT) [18, 20], that are depicted in Figs. 12 and 13 for the investigated lubricants.

As shown in Fig. 12, the POFPs change significantly from about $90 \mathrm{MPa}$ to $120 \mathrm{MPa}$ between the two different loads, but do not vary significantly between the different lubricants at the same load.

For a load of $41 \mathrm{MPa}$ the results show that the MOFT is for all investigated oil-classes above 1.5 $\mu \mathrm{m}$, which is the asperity contact threshold. Therefore, no metal-metal contact occurs, which can also be seen in the power losses shown in Fig. 9.

Further, it is interesting to note that the MOFT decreases by about $0.5 \mu \mathrm{m}$ for every decrease in SAE-class; while the MOFT is considerably large with $3 \mu \mathrm{m}$ at the point of maximum load for lubrication with SAE40, it decreases to about $2.5 \mu \mathrm{m}$ and $2.0 \mu \mathrm{m}$ for SAE30 and SAE20, respectively. For SAE10 the MOFT at the point of maximum load decreases further to about $1.5 \mu \mathrm{m}$; while from simulation still no asperity contact occurs for this case, in practical applications other effects not included here, like journal misalignment may lead to asperity contact.

The situation is quite different for a load of $70 \mathrm{MPa}$ where all oils cannot avoid a certain amount of asperity contact and the MOFT consequently drops for all oils below $1.5 \mu \mathrm{m}$, however, for a different number of degrees crank angle. It is instructive to note that for a load of $70 \mathrm{MPa}$ the MOFT changes not by the same amount between the different viscosity classes as for the $41 \mathrm{MPa}$ load case. This can be explained by the choice of the elastic factor in 


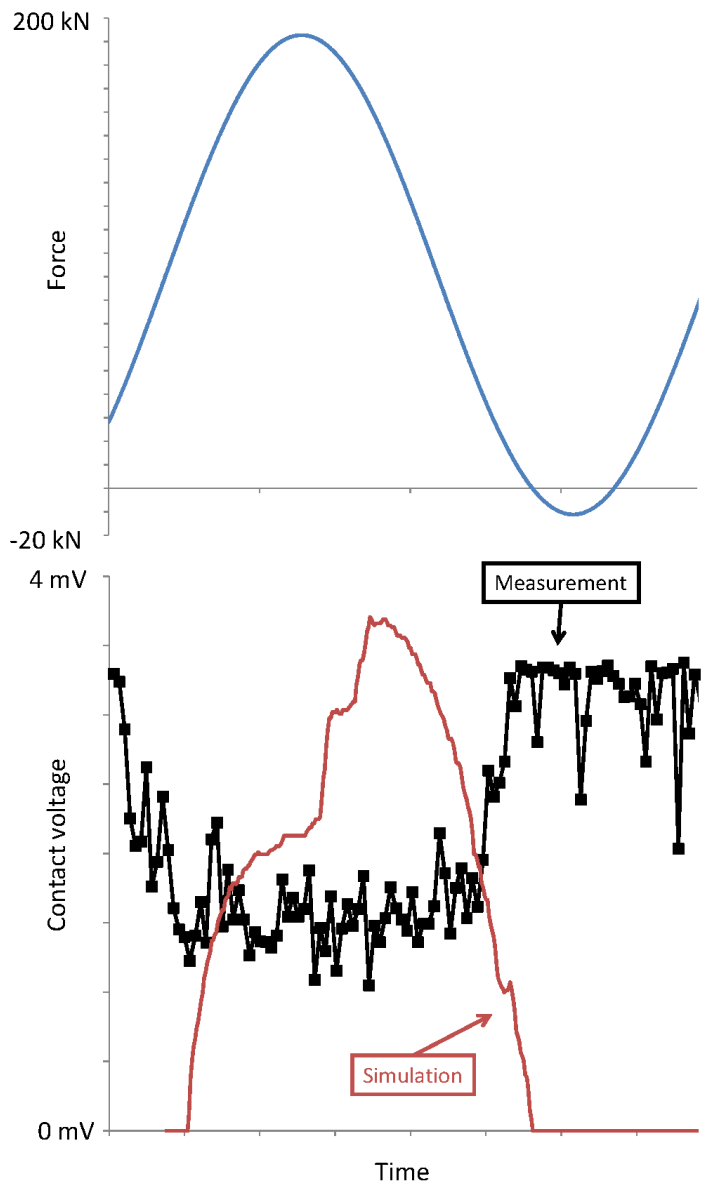

Figure 11. Plot of the measured contact voltage (black markers), whose decrease signals occuring metal-metal contact, in comparison to the metal-metal contact predicted from simulation (red line); as reference the blue curve depicts the applied load (top) for the bearing durability test.

the contact model that directly influences how much the asperity contact pressure increases for a given reduction in oil film thickness, see Eqs. (3) and (4). Due to the use of a large elastic factor, as discussed in Sec. 3.1.2, already small changes in oil film thickness lead to large changes in the asperity contact pressure and, therefore, increase significantly the total load carrying capacity.

In Fig. 10 this increase in asperity contact pressure is depicted over shell angle at the shell edge for lubrication with the different oils and a load of $70 \mathrm{MPa}$. As can be seen, the asperity contact pressure increases from a maximum of about 2.5 MPa for the SAE40-oil to a maximum 


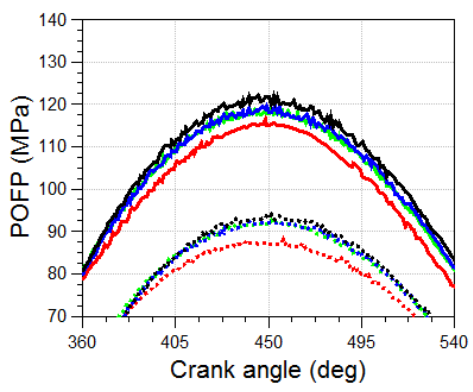

Figure 12. Plot of the calculated peak oil film pressures (POFP) occurring in the test bearing during the 90 degrees crank cycle when the load is applied (see Fig. 5); dashed lines denote the results for an applied load of $41 \mathrm{MPa}$, solid lines the results for an applied load of $70 \mathrm{MPa}$; the red curves represents the results for SAE10, the green for SAE20, the blue for SAE30 and the black curves show the results for lubrication with SAE40-oil.

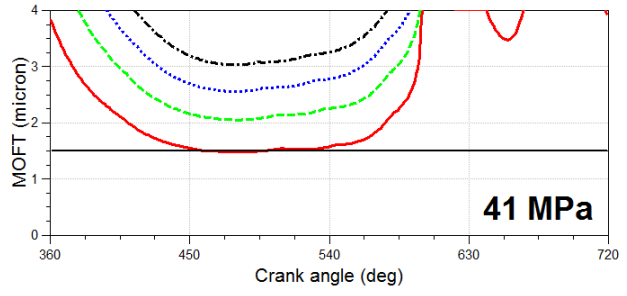

(a)

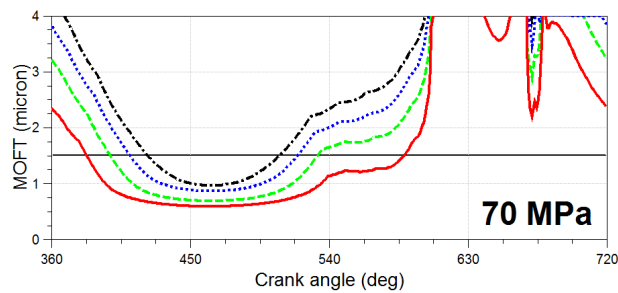

(b)

Figure 13. Comparison of the minimum oil film thickness (denoted as MOFT, unit in $\mu \mathrm{m}$ ) during a crank cycle in the test bearing for a load of (a) $41 \mathrm{MPa}$ and (b) $70 \mathrm{MPa}$ for 2000rpm journal speed calculated for the different oils: red solid line denotes SAE10, the green dashed line SAE20, the blue dotted line SAE30 and the black dash-dotted line SAE40. In addition the line at $1.5 \mu \mathrm{m}$ shows the threshold when asperity contact starts.

of $50 \mathrm{MPa}$ for lubrication with the SAE10-oil and this explains the small MOFT changes that are seen for the different oils.

The presented asperity contact pressures occur only at the outermost bearing shell edges and drop sharply within a few millimetres in axial direction, as shown in Fig. 14 exemplary for lubrication with SAE10 and a load of $70 \mathrm{MPa}$. The concentration of asperity contact in these areas is a consequence of the elastic deformation of the shell and journal under load and, therefore, these areas are particularly subject to wear. However, the exact shape of these areas depends also on the stiffness of the supporting structures.

This result further demonstrates the necessity of using realistic surface profiles in the simulation as otherwise asperity contact in these areas, and consequently also the friction moment, is largely overestimated. Performing an actual simulation for a load of $70 \mathrm{MPa}$ and a lubrication with SAE10 without the discussed surface profile for the test bearing, simulation predicts a power loss due to asperity contact of $389 \mathrm{~W}$ (averaged over a full crank cycle), which 


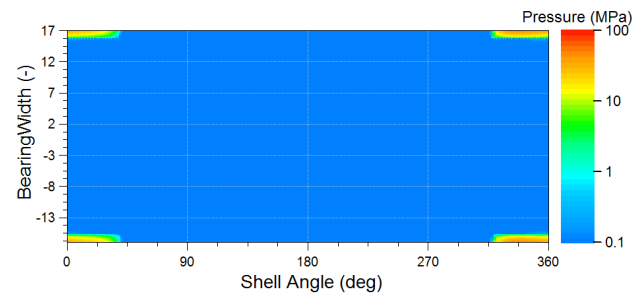

Figure 14. Map of the asperity contact pressures calculated for a load of $70 \mathrm{MPa}$ and lubricated with SAE10-oil: the largest asperity contact pressures occur in very small areas at the bearing edges and drop sharply off within a few millimetres. The regions displayed in blue represent full film lubrication.

\begin{tabular}{|c|c|c|c|c|}
\hline $\begin{array}{r}P_{\text {ACP }} \\
{[W]}\end{array}$ & $\begin{array}{c}P_{A C P}^{\text {noWP }} \\
{[\mathrm{W}]}\end{array}$ & $\begin{array}{c}\mathrm{M}_{\text {Sim }} \\
{[\mathrm{Nm}]}\end{array}$ & $\begin{array}{c}\mathrm{M}_{\text {Sim }}^{\text {noWT }} \\
{[\mathrm{Nm}]}\end{array}$ & $\begin{array}{c}\mathrm{M}_{\mathrm{LP06}} \\
{[\mathrm{Nm}]}\end{array}$ \\
\hline \hline 64 & 389 & 4.7 & 6.9 & $(4.4-4.8) \pm 0.5$ \\
\hline \hline
\end{tabular}

Table 2. Summary of the average friction moments predicted by simulation for a load of $70 \mathrm{MPa}$ and lubrication with SAE10: the simulation using a surface profile for the test bearing is denoted as $\mathrm{M}_{\text {Sim }}$ and denoted as $\mathrm{M}_{\mathrm{Sim}}^{\text {noWP }}$ is the simulation without surface profile for the test bearing. The experimental values are denoted as $\mathrm{M}_{\mathrm{LP} 06}$ (range in brackets, \pm measurement accuracy).

exceeds by more than a factor six the value obtained for the simulation with the wear profile, namely $64 \mathrm{~W}$, as shown in Fig. 9.

Consequently, simulation predicts for a load of $70 \mathrm{MPa}$ and lubrication with SAE10 an average friction moment of $6.9 \mathrm{Nm}$ which exceeds the experimental values by about $50 \%$, see Tab. 2 .

\subsubsection{Summary}

Summarizing, for all investigated working conditions the presented simulation approach achieves very good agreement with the measured values and all calculated average friction moments lie within the experimentally found value range.

From a methodological point of view we find from the results that the shown accuracy can only be obtained reliably if the following important points discussed in this work are used in combination: a pressure dependent oil-model is of crucial importance as the dominant pressure thickening of the lubricant allows an easy and straightforward temperature estimation for the global oil temperature used in the EHD-calculation (this is shown in more detail also in [2]). Further, to avoid a large overestimation of the power loss due to metal-metal contact, deviations from the nominal perfect geometry of the bearing due to wear have to be taken into account and, further, a reduced surface roughness is efficient in combination with the Greenwood and Tripp model to take into account the conformal character of the bearing surfaces.

The origins of friction, asperity contact and hydrodynamic losses are discussed for the investigated lubrication cases and it is found that for the lower load, namely for $41 \mathrm{MPa}$, simulation predicts that no asperity contact occurs for lubrication with all oils studied. 
Though the minimum oil film thickness found in simulation for SAE10 is very close to the threshold of asperity contact, all investigated oils are expected to provide sufficient lubrication for this load. The correspondingly calculated friction power losses demonstrate well the attainable friction reduction by choosing a lubricant with the optimum viscosity for a certain load; in particular, for a load of $41 \mathrm{MPa}$ the friction power losses can be reduced from $518 \mathrm{~W}$ for SAE40 down to $340 \mathrm{~W}$ for SAE10, which is a reduction by $33 \%$.

For the significantly more severe load case of $70 \mathrm{MPa}$, a certain amount of asperity contact is seen for all studied oils in the results from simulation. Indeed, the hydrodynamic friction power losses could be reduced from $626 \mathrm{~W}$ for the SAE40 oil to $453 \mathrm{~W}$ calculated for the SAE10 oil, which corresponds theoretically to almost a 30\% reduction in friction. However, power losses caused by metal metal contact diminish this potential by a certain extent. Still, the total friction power losses are reduced from $626.5 \mathrm{~W}$ for SAE40 to $517 \mathrm{~W}$ for SAE10, which is still a reduction by almost $20 \%$. This result demonstrates the efficiency in reducing friction by choosing a lubricant with reduced viscosity, so that, as long as measures to maintain reliability are taken (e.g. by using antiwear-additives in the lubricant), even a small amount of asperity contact might be tolerated to reduce the total friction power losses. This result is the starting point for the further work in Sec. 4

\subsection{Including thermal processes - TEHD}

Although the agreement of the previously presented simulation method with the experimental data is very much on spot and within the experimental accuracy for the whole range of working conditions studied, the neglect of local temperatures is a rough approximation of reality and its deviations to a model including local temperatures need to be quantified. In the following the isothermal simulation method is extended to a thermoelastohydrodynamic (TEHD) calculation to consider local temperatures. While critically important information like the bearing shell back temperatures was needed as input for the EHD simulation, these should now emerge from a representative thermal submodel. Due to the fact that the extension to TEHD is not straightforward and its thermal submodel adds a number of additional uncertain factors, the boundary conditions are chosen not only on a basis of physical arguments but also sufficiently distant from the oil film to minimize their influence on the results.

In the following the focus is on the extension of the isothermal simulation method to include local temperatures; therefore, all details regarding the experimental part are not repeated, but can be found in Section 3.1.

\subsubsection{Theory}

From a methodological point of view the TEHD-approach to journal bearings is well known; it adds the energy equation and heat equation to the set of differential equation that need to be solved together. While this approach represents a more complete picture of the physical processes in journal bearings, it has several severe drawbacks. While the dramatically increased cpu-time is more of a practical drawback that might be resolved by faster computers or faster solvers, the required thermal submodel needs a detailed knowledge of the thermal 
properties and of the heat flows of the test-rig. Therefore, subsection 3.2.4 is devoted to discuss its derivation.

Following [17] the Reynolds equation is combined with the energy equation to be able to take thermal processes into account. In a body shell fixed coordinate system such an extended Reynolds equation can be defined as $[17,23]$

$$
\begin{aligned}
& -\frac{\partial}{\partial x}\left(\theta \alpha^{2} \frac{\partial p}{\partial x}\right)-\frac{\partial}{\partial z}\left(\theta \alpha^{2} \frac{\partial p}{\partial z}\right)+ \\
& +\frac{\partial}{\partial x}(\theta \beta)+\frac{\partial}{\partial t}(\theta \gamma)=0,
\end{aligned}
$$

where $x, z$ denote the circumferential and axial directions and $\theta$ the oil filling factor. $\alpha, \beta, \gamma$ are defined as

$$
\begin{aligned}
-\alpha^{2} & =h^{3} \cdot \int_{0}^{1} \rho\left(\int_{0}^{y} \frac{y^{\prime}}{\eta^{\prime}} d y^{\prime}-\frac{\int_{0}^{1} \frac{y^{\prime}}{\eta^{\prime}} d y^{\prime}}{\int_{0}^{1} \frac{1}{\eta^{\prime}} d y^{\prime}} \cdot \int_{0}^{y} \frac{1}{\eta^{\prime}} d y^{\prime}\right) d y \\
\beta & =h \cdot U \int_{0}^{1} \rho\left(1-\frac{\int_{0}^{y} \frac{1}{\eta^{\prime}} d y^{\prime}}{\int_{0}^{1} \frac{1}{\eta^{\prime}} d y^{\prime}}\right) d y \\
\gamma & =h \int_{0}^{1} \rho d y,
\end{aligned}
$$

where the direction along the film height, $y$, is normalized to the oil film height $h$, thus the integration is carried out from 0 to 1 . Further, the prime $\left(^{\prime}\right)$ indicates that the corresponding quantity depends on $y^{\prime} . U$ is the difference of the circumferential speeds of journal and bearing shell, $U=U_{\text {Shell }}-U_{\text {Journal }} \cdot \eta$ and $\rho$ denote the oil viscosity and density, both are considered as pressure and temperature dependent.

The extended Reynolds equation (5) is solved together with the energy equation for the fluid film that is extended with the term $f($ Asp) to include heating due to asperity contact,

$$
\begin{aligned}
& \rho c_{p}\left\{\frac{\partial T}{\partial t}+u \frac{\partial T}{\partial x}+w \frac{\partial T}{\partial z}\right. \\
& \left.+\frac{1}{h}\left[v-y\left(\frac{\partial h}{\partial t}+u \frac{\partial h}{\partial x}+w \frac{\partial h}{\partial z}\right)\right] \frac{\partial T}{\partial y}\right\} \\
& +\frac{T}{\rho} \frac{\partial \rho}{\partial T}\left(\frac{\partial p}{\partial t}+u \frac{\partial p}{\partial x}+w \frac{\partial p}{\partial z}\right)-\frac{\kappa}{h^{2}} \frac{\partial^{2} T}{\partial y^{2}} \\
& =\frac{\eta}{h^{2}}\left[\left(\frac{\partial u}{\partial y}\right)^{2}+\left(\frac{\partial w}{\partial y}\right)^{2}\right]+f(\text { Asp }),
\end{aligned}
$$

where $\kappa$ denotes the thermal conductivity, $u, v, w$ refer to the $(x, y, z)$ components of the fluid velocity vector $\mathbf{v}$ at the corresponding fluid point and $c_{p}$ represents the specific heat of the 
lubricant. Eq. (7) considers heat convection in all three dimensions, heat conduction in radial direction, compression and viscous heating. $f(\mathrm{Asp})$ denotes the heating due to asperity contact,

$$
\begin{aligned}
f(\text { Asp }) & =\frac{\tau_{\text {Asp }}}{h^{3}} U \\
\tau_{\text {Asp }} & =\mu_{\text {Bound }} p_{\text {Asp }}
\end{aligned}
$$

where $\mu_{\text {Bound }}$ is the boundary friction coefficient and $p_{\text {Asp }}$ the asperity contact pressure calculated using the Greenwood and Tripp model with the same parameters as discussed in the previous section 3.1.

For the thermal analysis of the bearing shell and a part of its surrounding structure, the actual geometry is approximated by a cylinder; for this cylinder the heat equation

$$
\rho_{\mathcal{S}} \mathcal{C}_{S} \frac{\partial T_{S}}{\partial t}-\kappa_{S} \Delta T_{S}=0
$$

is solved with the continuity of the temperature and heat flow as boundary conditions. The subscript $s$ indicates that the quantities apply to this cylinder. As outer boundary condition of this cylinder to its ambient

$$
\frac{\partial T_{S}}{\partial n}+\frac{\lambda}{\kappa_{S}}\left(T_{S}-T_{R}\right)=0
$$

is used, where $T_{R}$ is a reference temperature and $\lambda$ the heat transfer coefficient to the ambient.

Last, as second outer boundary condition of the oil film to the journal, the journal temperature $T_{J}$ was assumed to be constant (isothermal boundary condition).

To calculate the oil temperature in the oil groove an energy balance equation is used

$$
\rho c_{p} V_{o} \frac{\partial T_{o}}{\partial t}=\int_{S_{o}}\left(\kappa_{S} \frac{\partial T_{S}}{\partial r}-\kappa \frac{\partial T}{\partial y}\right) d S+\rho c_{p} \Phi\left(T_{o}^{\prime}-T_{o}\right)
$$

that takes into account that a certain amount of hot oil is carried over the cavitation zone and mixes with the cold oil supplied to the oil groove. Also heat conduction between oil and bearing shell is considered. $V_{o}$ denotes the volume and $S_{o}$ the area of the oil groove, $T_{o}$ the actual oil temperature in the oil groove, $T_{o}^{\prime}$ the supply temperature of the oil and $\Phi$ the oil flow from the groove into the bearing.

\subsubsection{Simulation}

The experimental data for the basic lubricant properties, namely density and dynamic viscosity, were already shown in the previous Section 3.1.2. In addition also the thermal lubricant properties are needed for the TEHD-simulation: specific heat and heat conductivity. These properties have also been measured for the same lubricant samples in the OMV-laboratory and the measured data are shown for the used SAE20 and SAE40 lubricant in Fig 15. 


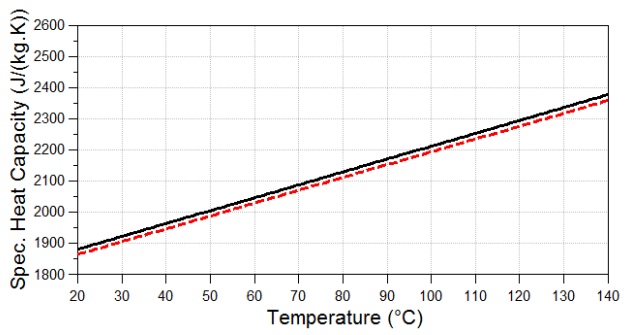

(a)

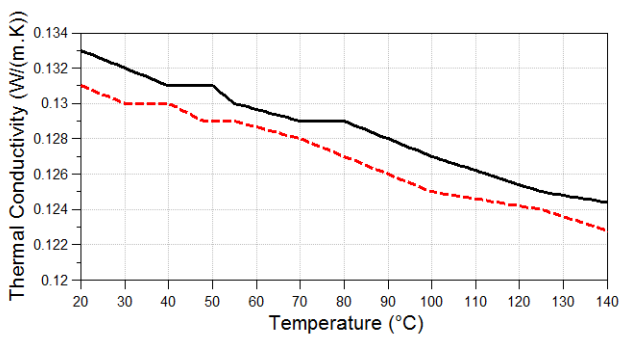

(b)

Figure 15. Plot of (a) the specific heat $c_{p}$ and (b) thermal conductivity $\kappa$ of the used lubricant, shown as black solid line for SAE20 and as red dashed line for SAE40.

In the previous Section 3.1 the results from simulation were compared to the full range of values experimentally observed in repeated test runs; repeating the measurements with different, but brand new bearings resulted in measured total friction moments and temperatures that varied significantly between runs. Also, the quoted measurement uncertainty is significantly enlarged due to these repetitions.

For the following calculations the temperature data from a single test run for each lubricant/journal speed case is used to setup the thermal submodel of the TEHD calculation. Consequently, the results from the simulations are compared to these single test runs and the quoted smaller measurement uncertainty no longer contains the additional error due to repeating the test-runs with new bearings. Consequently, the measurement uncertainty is only about half of the previous measurement uncertainty, which represents a much stricter test for simulation.

\subsubsection{The thermal submodel}

On the test-rig a number of temperatures were measured together with the total friction moment that are either directly incorporated into the thermal submodel or used to validate it: notably the three bearing shell back temperatures, two con rod temperatures and the oil outflow temperature. The corresponding temperatures were measured by using thermocouple elements of type $\mathrm{K}$ that have an accuracy of $\pm 1^{\circ} \mathrm{C}$. The three bearing shell back temperatures were located at $\pm 45^{\circ}$ circumferential angle from the vertical axis and the third in the middle at $0^{\circ}$ circumferential angle as shown in Fig. 4 and represent, consequently, the temperatures in the high load area of the journal bearing.

On the con rod of the test-rig the temperature was measured in addition at $41 \mathrm{~mm}$ distance from the bearing shell's inner diameter at two axial positions close to the high load zone. Last, the oil outflow temperature was also measured; Table 5 lists all these values.

A representative choice of the boundary conditions for the journal and to the ambient is of crucial importance as these affect the thermal flows in the system.

For the heat transfer coefficient $\lambda$ of Eq. (10) a value of $120 \frac{\mathrm{W}}{\mathrm{m}^{2} \mathrm{~K}}$ is used, which lies within the range of typically used values $[7,14,28,29]$. The test con rod is made of $42 \mathrm{CrMo} 4$ and to 
describe its thermal behaviour a thermal conductivity of $\kappa_{S}=46 \frac{\mathrm{W}}{\mathrm{m} R}$ and specific heat capacity of $c_{s}=460.5 \frac{\mathrm{J}}{\mathrm{kg} \mathrm{K}}$ are used (see also Table 3 ).

Further, the journal is assumed to be isothermal which sufficiently well approximates the real surface temperature as its circumferential speed is significantly larger than typical heat flow processes [17]. The journal temperature $T_{J}$ is the only adjustable property in the simulation model and it is chosen such that the calculated bearing shell back temperatures averaged over one cycle, $T_{1}^{\text {Sim }}, T_{2}^{\text {Sim }}, T_{3}^{\text {Sim }}$, agree well with the corresponding experimental values $\left(T_{1}^{\text {Exp }}, T_{2}^{\text {Exp }}\right.$, $\mathrm{T}_{3}^{\text {Exp }}$ ), see Table 5 .

Outward of the oil film $25 \mathrm{~mm}$ of the surrounding structure are taken into account in the thermal analysis; as reference temperature, denoted as $T_{R}$ in Eq. (10), a value is used that was measured in the con rod of the test-rig at $41 \mathrm{~mm}$ distance from the bearing shell's inner diameter at two axial positions close to the high load zone. The used values for $T_{R}$, obtained by averaging the aforementioned two experimental values, are listed in Table 4.

The current model does not account for thermoelastic deformations and the consequent changes in bearing clearance. In the previous EHD-simulations a value for the bearing clearance was used that was measured experimentally at room temperature. While this simplification appears not to significantly affect the calculation of the total friction moment, the in this way calculated oil flow through the bearing does not agree well with the actual experimental oil flow. Therefore, the thermal power leaving the bearing with the oil-outflow cannot be expected to be calculated reliably. As consequence, it is attempted in the following to at least partially include thermoelastic effects by scaling the bearing clearance in the TEHD-calculations such that the oil flow through the bearing agrees with the experimentally controlled oil-flow of 2 litres per minute.

Further, it appears from the results that the such adapted bearing clearance has no other major impacts on the thermal submodel as the bearing shell temperatures experience only single degree changes.

As the amount of oil flow through the bearing is then properly included in the simulation, this further allows to calculate an approximative value ${ }^{5}$ of the mean oil outflow temperature due to the power losses in the bearing and compare this value to the corresponding measured oil outflow temperature.

The mean temperature increase of the lubricant after flowing through the bearing, $\Delta T$, is calculated using the thermal power leaving the bearing with the lubricant, $P_{\text {oil out }}$, using

$$
\Delta T=\frac{P_{\text {oil out }}}{c_{p} \rho}\left(\frac{V}{t}\right)^{-1},
$$

where $c$ and $\rho$ denote the specific heat capacity and density of the lubricant, respectively, and $\frac{V}{t}$ is the oil volume flow through the bearing. The approximative mean oil outflow

\footnotetext{
${ }^{5}$ As we use a commercial software package we do not have access to the required numerical data to realize an exact scheme.
} 


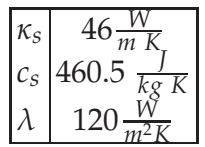

Table 3. Table of the values used for the thermal conductivity $\kappa$, specific heat capacity $c_{S}$ and the heat transfer coefficient $\lambda$ of the test con-rod as denoted in Eqs. (9) and (10).

\begin{tabular}{|l|c|c|c|}
\hline oil & \multicolumn{2}{|c|}{ SAE40 } & SAE20 \\
speed [rpm] & 2000 & 4500 & 2000 \\
\hline$T_{J}\left[{ }^{\circ} \mathrm{C}\right]$ & 107 & 134 & 98 \\
$T_{R}\left[{ }^{\circ} \mathrm{C}\right]$ & 101 & 118 & 98 \\
\hline
\end{tabular}

Table 4. List of the values for the reference temperature $T_{R}$, as employed in Eq. (10), and the constant journal temperature $T_{J}$ used for the different investigated cases of journal speed and lubrication.

\begin{tabular}{|l|c|c|c|}
\hline oil & \multicolumn{2}{|c|}{ SAE40 } & SAE20 \\
speed [rpm] & $\mathbf{2 0 0 0}$ & $\mathbf{4 5 0 0}$ & $\mathbf{2 0 0 0}$ \\
\hline $\mathrm{T}_{\text {oil supply }\left[{ }^{\circ} \mathrm{C}\right]}$ & 82.2 & 83.0 & 82.2 \\
$\mathrm{~T}_{\text {oil groove }}^{\text {Sim }}\left[{ }^{\circ} \mathrm{C}\right]$ & 83.4 & 84.5 & 82.2 \\
\hline $\mathrm{T}_{\text {oil out }}^{\text {Sim }}\left[{ }^{\circ} \mathrm{C}\right]$ & 94.0 & 109.7 & 89.6 \\
$\mathrm{~T}_{\text {oil out }}^{\text {Exp }}\left[{ }^{\circ} \mathrm{C}\right]$ & $93 \pm 1$ & $110 \pm 1$ & $91 \pm 1$ \\
\hline $\mathrm{T}_{1}^{\text {Sim }\left[{ }^{\circ} \mathrm{C}\right]}$ & 101.6 & 123.3 & 95.6 \\
$\mathrm{~T}_{1}^{\operatorname{Exp}}\left[{ }^{\circ} \mathrm{C}\right]$ & $103 \pm 1$ & $124 \pm 1$ & $95 \pm 1$ \\
\hline $\mathrm{T}_{2}^{\operatorname{Sim}}\left[{ }^{\circ} \mathrm{C}\right]$ & 107.6 & 136.8 & 98.5 \\
$\mathrm{~T}_{2}^{\operatorname{Exp}}\left[{ }^{\circ} \mathrm{C}\right]$ & $108 \pm 1$ & $138 \pm 1$ & $98 \pm 1$ \\
\hline $\mathrm{T}_{3}^{\operatorname{Sim}}\left[{ }^{\circ} \mathrm{C}\right]$ & 106.9 & 137.3 & 98.7 \\
$\mathrm{~T}_{3}^{\operatorname{Exp}}\left[{ }^{\circ} \mathrm{C}\right]$ & $107 \pm 1$ & $136 \pm 1$ & $93 \pm 1$ \\
\hline
\end{tabular}

Table 5. Comparison of various measured temperatures with the corresponding calculated temperatures from simulation; $\mathrm{T}_{1}, \mathrm{~T}_{2}, \mathrm{~T}_{3}$ denote the cycle averaged bearing shell back temperatures according to Fig. 4 , where the superscript Sim denotes the calculated and Exp the measured values; $\mathrm{T}_{\text {oil out }}^{\text {Sim }}$ and $\mathrm{T}_{\text {oil out }}^{\text {Exp }}$ represent the calculated and measured oil outflow temperatures. Further, $\mathrm{T}_{\text {oil supply denotes the oil }}$ supply temperature (same for simulation and test-rig) and $\mathrm{T}_{\text {oil groove }}^{\mathrm{Sim}}$ denotes the calculated oil temperature in the oil groove (see text). Finally, oil denotes the lubricant and speed the journal speed.

temperature is then calculated by

$$
T_{\text {oil out }}=T_{\text {oil supply }}+\Delta T \text {. }
$$

As the lubricant properties $c_{p}$ and $\kappa$ themselves depend on the temperature, this procedure is only approximative.

In the following a number of results for different working conditions ranging from full film lubrication (SAE40 and 4500rpm journal speed) to the onset of mixed lubrication (SAE20 and 2000rpm journal speed) are discussed.

\subsubsection{Results for the thermal submodel}

As shortly outlined in the introduction of this section, extending the EHD-simulation to TEHD brings significant additional complexity due to the thermal submodel that has to be 


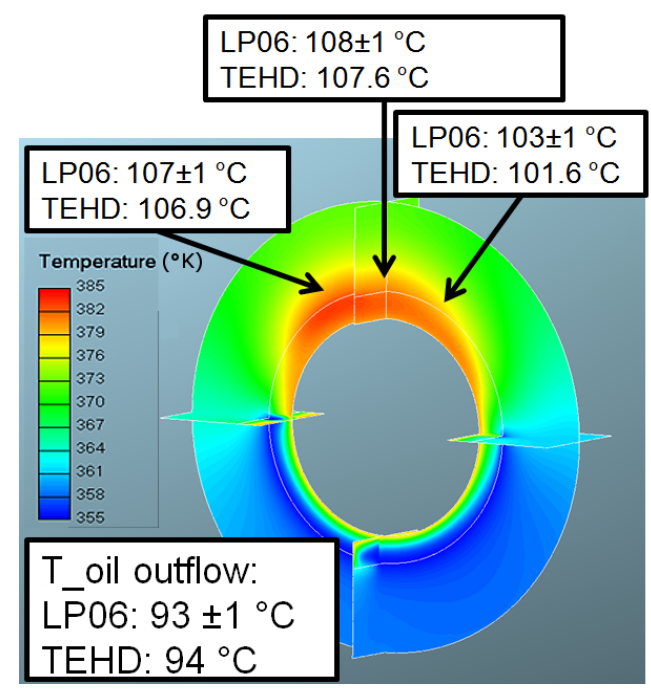

Figure 16. Plot of the temperatures occuring in the oil film and surrounding bearing structure in the axial center of the bearing for the exemplary case of lubrication with SAE40 and a load of $70 \mathrm{MPa}$ at a journal speed of 2000rpm. LP06 denotes the values measured on the test-rig and TEHD the values calculated with the TEHD-method. In addition the mean oil outflow temperature calculated from TEHD, $T_{\text {oil outflow }}$, is compared to the experimentally measured value. The thin white line represents the border between oil film and bearing structure (the oil film is drawn disproportionately large).

employed. As the local temperatures directly influence the lubrication properties within the bearing the thermal submodel needs to be validated with experimental measurements. Table 5 contains for all cases studied the temperatures calculated at several points of the test-rig and allows to compare these to the corresponding measured temperatures, in particular Fig. 16 shows a graphical comparison for lubrication with the SAE40 lubricant and a journal speed of 2000rpm. As previously mentioned it is the aim to choose the journal temperature for each case such that the calculated bearing shell temperatures agree within about $1^{\circ} \mathrm{C}$ with the measured temperatures; this could be achieved for all cases except for the SAE20 result, where one of the three bearing shell temperatures deviates from the measured one by about $5^{\circ} \mathrm{C}$.

As the temperature of the whole test-rig lies above the oil inflow temperature only the friction power losses in the bearings heat the system. Therefore, as an additional validation the calculated (see Eq. 12 and 13) and measured oil outflow temperatures are compared in Table 5. As one can see from these results the predicted mean oil outflow temperature agrees for all cases within $1^{\circ} \mathrm{C}$ with the measured mean oil outflow temperatures. Summarizing, the results confirm that the thermal submodel is suitably chosen and representative for the test-rig.

For sake of completeness Table 5 also lists the actual oil temperatures in the oil groove that are calculated for each case as defined by Eq. (11). From the results one finds that the actual oil temperature in the oil groove is only weakly affected by the surrounding hotter structure as the temperature differences are very small for all cases. 


\subsubsection{Results for the friction power losses}

In the following the results obtained with the various methods are discussed in terms of friction prediction; to this task the results from TEHD are compared to the results obtained from EHD. As the TEHD comes with a largely increased cpu-time requirements, only the test-bearing is investigated using TEHD in the following.

As briefly mentioned in Sec. 3.1, the discussed EHD-simulation model employs the same lubricant temperature for test and support bearings. This restriction needs to be removed first to allow consequently a detailed comparison of the results for the test-bearing obtained from different simulation methods.

In [1] a new method is proposed that allows to easily calculate a suitable oil film temperature for the isothermal EHD-calculation. The procedure combines the measured bearing shell temperature, $T^{\text {Exp }}$, and the supplied oil temperature, $T_{\text {oil supply }}$, to

$$
T^{\text {comp }}=T^{\text {Exp }}-\frac{T^{\text {Exp }}-T_{\text {oil supply }}}{4}
$$

and yields the same accurate results as can be seen in Figs. 17 and 18, but has the advantage of being applicable to single bearings. For reference also shown are the results that are obtained from the same EHD model but with the previously in Sec. 3.1 discussed temperature estimation for all three combined bearings.

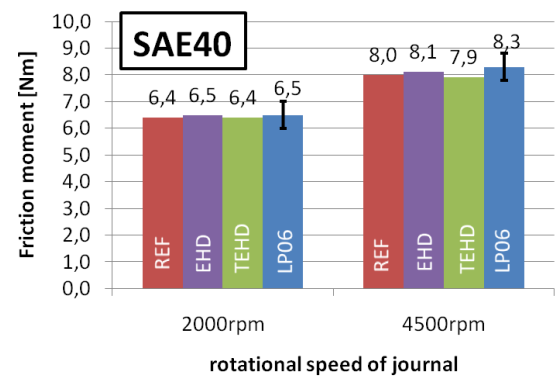

Figure 17. SAE40, $70 \mathrm{MPa}$ : comparison of the total friction moments calculated by EHD and TEHD to the experimental values measured on the test-rig LP06; the black bars denote the measurement accuracy of $\pm 0.5 \mathrm{Nm}$. Denoted as $R E F$, the values calculated by the previous temperature estimation method of Sec. 3.1 are shown for reference (see text).

As a first test for both new methods (TEHD-simulation of the test-bearing and the new method to obtain a representative lubricant temperature for the EHD-simulation of the support bearings), again the total friction moment for all three bearings is compared to the experimental data.

Starting with working conditions within full film lubrication, Fig 17 shows the total friction moment calculated by EHD and TEHD and gives a comparison to the experimental values for SAE40 and two different journal speeds. As can be seen the TEHD-results do not show systematic deviations that might be expected due to the inclusion of local temperatures. In 
fact, the results are almost identical; for a journal speed of 2000rpm $6.4 \mathrm{Nm}$ are calculated by TEHD in comparison to the $6.5 \mathrm{Nm}$ predicted by EHD and the $6.5 \pm 0.4 \mathrm{Nm}$ measured on the test-rig. For an increased journal speed of 4500rpm the results are again very close with $7.9 \mathrm{Nm}$ and $8.1 \mathrm{Nm}$ predicted by TEHD and EHD, respectively, compared to the $8.3 \pm 0.5 \mathrm{Nm}$ measured experimentally.

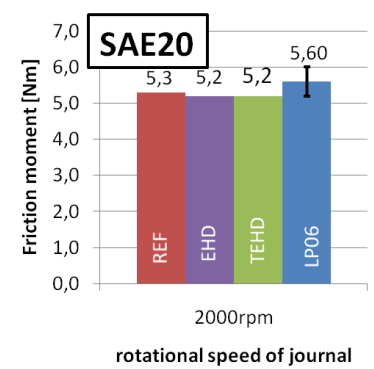

Figure 18. SAE20, $70 \mathrm{MPa}$, 2000rpm: comparison of the total friction moments calculated by EHD and TEHD to the experimental value measured on the test-rig LP06; the black bars denote the measurement accuracy of $\pm 0.5 \mathrm{Nm}$. Denoted as $R E F$, the values calculated by the previous temperature estimation method of Sec. 3.1 are shown for reference (see text).

For the case of SAE20 and a journal speed of 2000rpm weak mixed lubrication occurs. As Fig. 18 depicts, even the same total friction moment is calculated by both methods for this working condition.

For reference Figs. 17,18 also show the results calculated with the previously in Sec. 3.1 discussed method, where the same lubricant temperature was used in the EHD-simulations of all three bearings. This procedure is not suited to discuss properties of the individual bearings and it is only shown for completeness. As can be seen from the results for the total friction moment, the previously proposed method is very accurate.

While the total friction moment arises from all three bearings, the details of the calculated friction power losses are discussed in the following focusing on the test-bearing only. As was found in Sec. 3.1, for a load of $70 \mathrm{MPa}$ and a journal speed of 4500rpm SAE40 oil provides sufficient lubrication such that the test bearing stays in the full film lubrication regime. This is also supported by the results obtained from the TEHD-calculation, where the individual contributions to the power losses are depicted in Fig. 19.

For the case of lubrication with SAE40 and a journal speed of 2000rpm the hydrodynamic power losses calculated by both methods are very close with a difference of $5 \%$. The TEHD-model takes into account the hotter bearing shell temperatures at the edges of the bearing in the high load zone and, as consequence, a vanishing amount of metal-metal contact occurs. For the case of a journal speed of 4500rpm the differences between the results from EHD and TEHD increase to about $9 \%$.

For the case of weak mixed lubrication (lubrication with SAE20 and a journal speed of 2000rpm) the results (shown in Fig. 20) are again very close and differ only by about $5 \%$ 


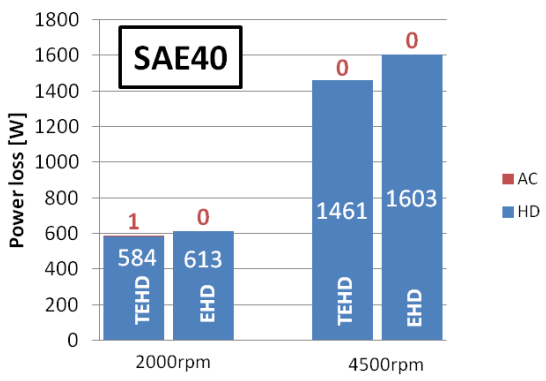

Figure 19. Comparison of the power losses in the test-bearing calculated with EHD and TEHD, respectively, for lubrication with SAE40 and a journal speed of 2000rpm (left) and 4500rpm (right). HD denotes hydrodynamic power losses and $A C$ power losses caused by metal-metal contact. The numbers denote the quantities of the corresponding contributions.

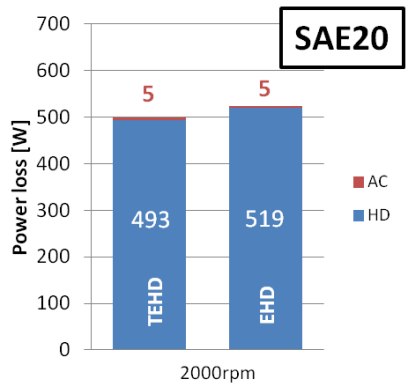

Figure 20. Comparison of the power losses in the test-bearing calculated with EHD and TEHD, respectively, for lubrication with SAE20 and a journal speed of 2000rpm. HD denotes hydrodynamic power losses and $A C$ power losses caused by metal-metal contact. The numbers denote the quantities of the corresponding contributions.

in terms of the hydrodynamic power loss. It is interesting to note that both methods predict about the same (small) amount of power loss due to metal-metal contact.

\subsubsection{A detailed TEHD vs. EHD comparison}

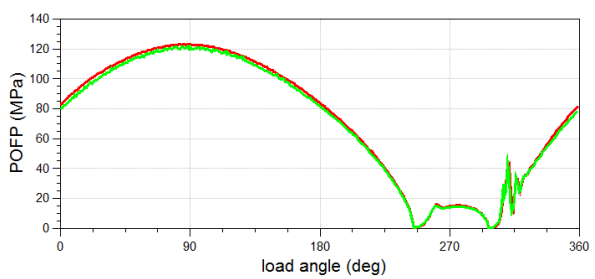

Figure 21. Exemplary plot of the peak oil film pressures (POFP) calculated with TEHD (red line) and with EHD (green line) for lubrication with SAE40 and a load of $70 \mathrm{MPa}$ at a journal speed of 2000rpm. 
However, while so far the differences between the EHD and TEHD-results have been rather small, the calculated lubricant viscosities are expected to be notably different. Although the calculated hydrodynamic pressures in the journal bearing match closely as Fig. 21 shows, differences arise due to different local temperatures.
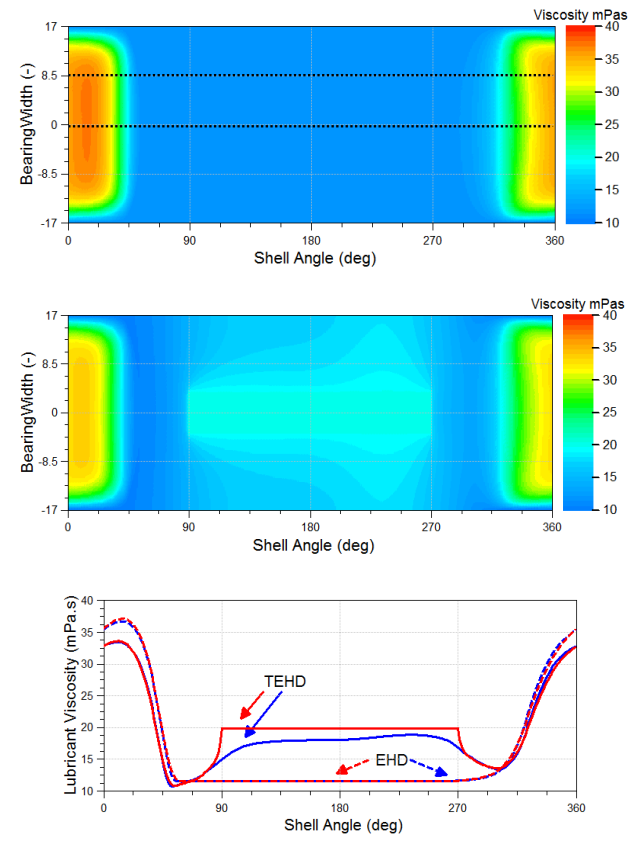

Figure 22. Plot of the oil viscosity in the test bearing at the point of maximum load for lubrication with SAE40 and a journal speed of 2000rpm, calculated with EHD (top) and TEHD (middle) using the same scale for comparison. For a detailed comparison the plot at the bottom shows the lubricant viscosity from EHD (dashed lines) and from TEHD (solid lines) over shell angle across $8.5 \mathrm{~mm}$ (blue lines) and $0 \mathrm{~mm}$ (red lines) bearing width (position of these cuts shown as black dashed lines in the plot on top). The rectangle shaped area with cool (thick) lubricant in the TEHD-results is the oil supply groove that cannot be taken into account directly in the EHD-calculation.

As can be seen in Fig. 22, the lubricant viscosities show significant differences. For the shown two different axial cuts through the high load zone the EHD-result predicts a maximum lubricant viscosity that is about $9 \%$ higher than the corresponding value calculated by TEHD. This $9 \%$ difference in lubricant viscosity corresponds roughly to a difference of only about $4^{\circ} \mathrm{C}$ in lubricant temperature (for SAE40) (see lubricant data in [3]). Consequently, this further confirms that the EHD-method with the proposed temperature compensation describes well the lubrication conditions also in the high load zone of the bearing.

\subsubsection{Dynamic behaviour of the local oil film temperatures}

Further, to quantify the approximation of the true bearing by using an isothermal EHD-model the lubricant temperatures close to the bearing shell are plotted in Fig. 23 for the exemplary 


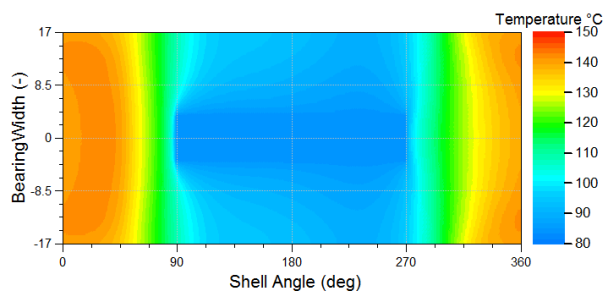

Figure 23. Plot of the calculated oil temperatures adjacent to the bearing shell for lubrication with SAE40 and a journal speed of 4500rpm at the point of maximum load (see Fig. 5); the actual maximum oil temperature in this plot is $144^{\circ} \mathrm{C}$ (see also Fig. 24).

case of SAE40 and a journal speed of 4500rpm, at the point of maximum load. These results show that spatially the oil temperature is almost constant in the high load area of the bearing (small temperature gradients in large areas of the bearing). Of course as the load changes the power losses in the oil film change and, consequently, local heating changes. Therefore, the dynamic change of the maximum lubricant temperature over a load cycle is shown in Fig. 24 for all cases studied. From these results one finds that the temperature variations in the journal bearing during one load cycle stay with about $2^{\circ} \mathrm{C}$ and are, therefore, also rather small. The observation that the temperature changes in the journal bearing are very small is in fact not new, it was e.g. discussed in [17]. The reasons behind this behaviour is on one hand that most of the heat (about $70 \%$ for the cases studied here) leaves the system with the oil and on the other hand that the thermal conductivity of steel is rather poor.

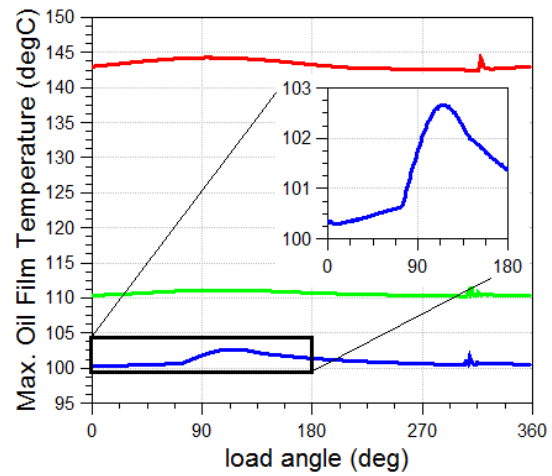

Figure 24. Plot of the maximum oil temperatures evolving over a load cycle for lubrication with SAE40 and a journal speed of 4500rpm, shown as red curve, for 2000rpm shown as green curve, and for lubrication with SAE20 and a journal speed of 2000rpm shown as blue curve. As metal-metal contact occurs in the SAE20-case this result consequently shows also the largest changes in the maximum oil film temperature. However, as the inset shows also for this case the maximum temperature change during one load cycle stays within about $2^{\circ} \mathrm{C}$.

As was argued already in Sec. 3.1, the high load area dominates the power losses in the bearing due to the occurrence of high hydrodynamic pressures of more than $100 \mathrm{MPa}$ in this area. 


\begin{tabular}{|l|c|c|c|c|c|}
\hline oil & run & $\begin{array}{c}\text { speed } \\
{[\mathrm{rpm}]}\end{array}$ & $\begin{array}{c}\mathrm{M}_{\mathrm{EHD}} \\
{[\mathrm{Nm}]}\end{array}$ & $\begin{array}{c}\mathrm{M}_{\text {TEHD }} \\
{[\mathrm{Nm}]}\end{array}$ & $\begin{array}{c}\mathrm{M}_{\mathrm{LP06}} \\
{[\mathrm{Nm}]}\end{array}$ \\
\hline \hline \multirow{2}{*}{ SAE40 } & \multirow{2}{*}{364} & 2000 & 6.4 & 6.6 & $6.5 \pm 0.4$ \\
& & 4500 & 8.0 & 8.0 & $8.3 \pm 0.5$ \\
\hline SAE20 & 377 & 2000 & 5.3 & 5.3 & $5.6 \pm 0.5$ \\
\hline
\end{tabular}

Table 6. Table of the total friction moments predicted by EHD, denoted as $\mathrm{M}_{\mathrm{EHD}}$, by TEHD, denoted as $\mathrm{M}_{\mathrm{TEHD}}$, and the corresponding total friction moment ( \pm measurement accuracy), denoted as $\mathrm{M}_{\mathrm{LP} 06}$, measured for the indicated run of which the temperature data was used to setup the thermal submodel of the TEHD-calculation. Speed denotes the journal speed and all data apply to the transient load with a maximum value of $70 \mathrm{MPa}$.

These pressures lead to a more than threefold viscosity increase of the lubricant in this part of the bearing. As the lubricant temperature varies only weakly in this area (both spatially as well as dynamically), it is indeed well described by the previously proposed isothermal EHD-approach [3] that takes into account the pressure dependence of the lubricant viscosity.

\subsubsection{Summary}

Within this section the previously discussed EHD-based simulation model was extended to TEHD to investigate differences arising due to the neglect of local temperatures. With the experimentally obtained temperature data for each working condition it was possible to validate the thermal submodel of the TEHD-method. By choosing appropriate thermal boundary conditions it was shown that the TEHD-method is able to predict the occurring temperatures at several different points of the test-rig, namely three bearing shell back temperatures and the oil outflow temperature, very accurately within $1{ }^{\circ} \mathrm{C}$ of the measured temperatures (with only one exception where the temperature difference is still rather small with $\left.5^{\circ} \mathrm{C}\right)$.

Concerning the ability to predict friction power losses in journal bearings, the results indicate that the considerably simpler EHD-approach appears to be sufficient to reliably and accurately predict these losses for full film lubrication. Also for weak mixed lubrication, as was studied using the SAE20 lubricant, the neglect of local temperatures results again only in small deviations that do not significantly affect the studied properties.

As was shown from the TEHD-results, the temperature in the high load zone stays almost constant throughout the load cycle and is also almost constant spatially within this high load zone; due to this temperature stability the EHD-method works very well.

In conclusion, the results demonstrate that even for highly loaded journal bearings as they are common in today's diesel and gasoline engines the EHD-method is still well suited to study the bearing working conditions, both in terms of the generated friction power losses and to investigate the occurrence of metal-metal contact. The inclusion of local temperatures in the form of an extension to TEHD does not give significant changes for full film and weakly mixed lubrication for the properties studied. It is, however, expected to be of more importance in mixed lubrication with significantly more metal-metal contact. However, such severe operating conditions do not occur in serially produced engines and are, therefore, not within the scope of this work. 


\section{Friction reduction for engines - a practical example}

In the following, the potential for friction reduction in the journal bearings of the crank train shall be analysed for a modern four cylinder passenger car turbodiesel engine lubricated with common multi-grade oils using the isothermal method discussed in Sec. 3.1. In particular, Styrene-Isoprene-Copolymer (SICP)-additive enhanced oils are considered in the following (in terms of shear rate dependency of the lubricant). For all variants, the friction will be calculated as sum of all five crankshaft main bearings and four big end bearings at full-load operation with a peak cylinder pressure of 190 bar, which leads to specific bearing loads of up to about $50 \mathrm{MPa}$ for the main bearings and to about $90 \mathrm{MPa}$ for the big end bearings. Further, the dynamic oil supply for the big end bearings is realistically represented in the simulation as oil supply network.

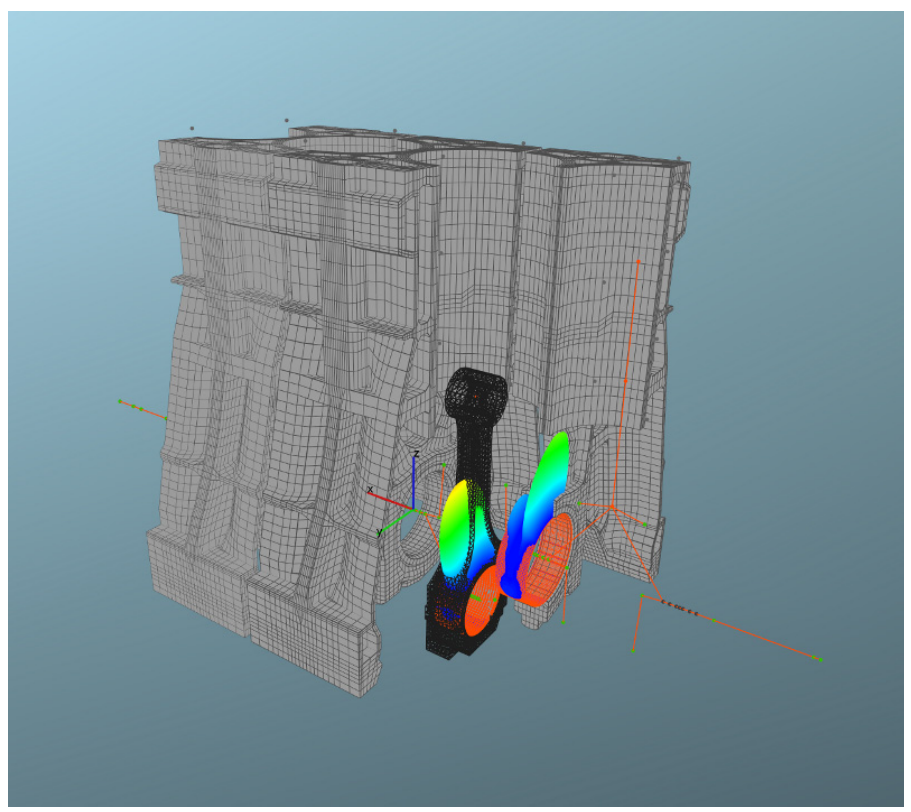

Figure 25. Plot of a part of the inline four cylinder engine for which the calculations are carried out; it shows the locations of the main and big end bearings which are shown with examplary oil film pressure distributions shown as 3D-plot.

\subsection{Finding a friction optimized solution}

In the following basic example, easily modifiable parameters such as bearing shell width and viscosity grade (SAE-class) of the engine oil are in the focus. The savings potential derived from the reduction of the bearing shell width is set with the reduction of the oil-filled volume and the use of low viscosity oils directly influences the viscosity losses. Both measures reduce the load capacity of the bearings. Therefore, it is crucial to identify occurring mixed lubrication in order to find a low friction solution which does not impair the bearing lifetime through emerging mixed lubrication. To illustrate the influence of the bearing shell width on the 
friction losses, widths of $21 \mathrm{~mm}$ and $16 \mathrm{~mm}$ are studied in addition to the original width of $18 \mathrm{~mm}$. Further, the original lubricant-grade $10 \mathrm{~W} 40$ is reduced to $0 \mathrm{~W} 30$ and for a specific case to $0 \mathrm{~W} 20$. Two different oil temperatures are considered in the simulation because in everyday life not only warm engine conditions exist, but also low oil temperatures occur specifically with low exterior temperatures or for short driving distances. For the warm engine operation $100^{\circ} \mathrm{C}$ and for the cool operation $40^{\circ} \mathrm{C}$ oil temperature is considered.

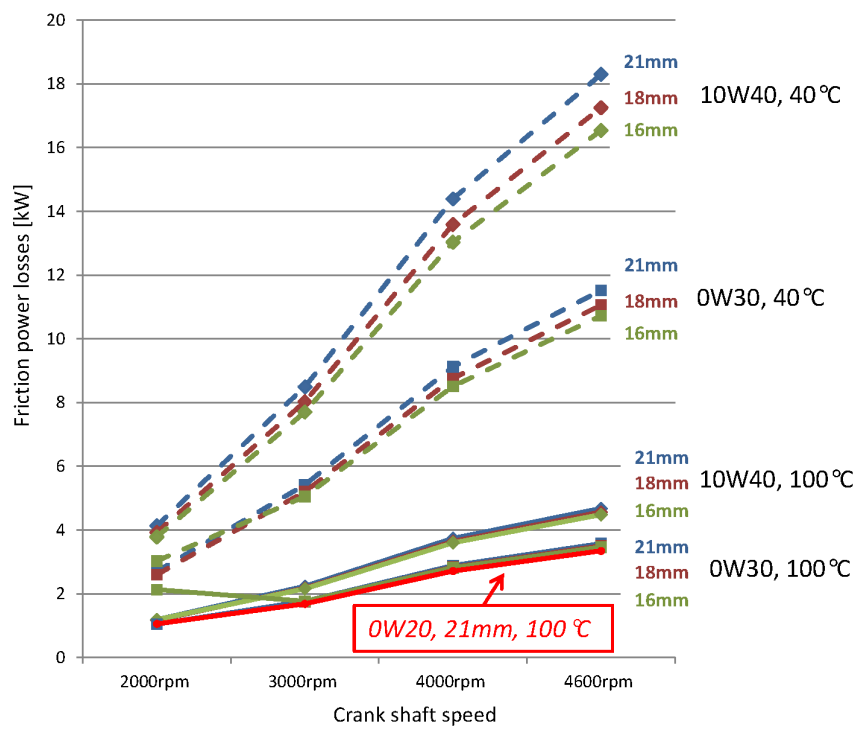

Figure 26. Friction power losses in the journal bearings at various speeds for different bearing shell widths, lubricant viscosity grades and operating temperatures.

Fig. 26 shows the summary of all results evaluated through the total friction power losses for all journal bearings at different speeds. Most notable from the results is that the oil temperature impacts the friction performance most intensely which is taken advantage of by many modern engines through a reduction of the oil volume in the oil sump and the related quicker warming-up of the engine. In particular, the friction power losses are cut in half throughout the entire speed range by increasing the lubricant temperature from $40^{\circ} \mathrm{C}$ to $100^{\circ} \mathrm{C}$. Furthermore, it is shown that the different oil viscosities have a much stronger effect than the changes in bearing width. Referring to the example a savings potential is found to be in average $35 \%$ for the cold and still $20 \%$ for the hot case through changing from $10 \mathrm{~W} 40$ to 0W30. In contrast, using more narrow bearings leads to a reduction of the losses by $9 \%$ for the cold case and a high speeds, but yields only a reduction of max $3 \%$ of the total journal bearing losses for the studied hot lubricant temperature. This minimal impact can be employed to use even lower viscosity oil for the engine and - while the load carrying capacity by utilizing wider bearings needs to be restored for this lubricant - a net reduction of friction power losses can be achieved. Fig. 26 also shows how the presented method assists in identifying potential issues of mixed lubrication: for the case of a $16 \mathrm{~mm}$ wide bearing and lubrication with $0 \mathrm{~W} 30$ there 
occurs for a lubricant temperature of $100^{\circ} \mathrm{C}$ already significant metal-metal contact at 2000rpm which leads to a significant rise in friction for this engine and potentially to problems in the operating reliability. However, with an enlarged bearing width even lower viscosity oil can be used; for the case presented the optimum is a low viscosity $0 \mathrm{~W} 20$ oil combined with a broader bearing shell, in this case $21 \mathrm{~mm}$. Thereby, in comparison to the original configuration with $18 \mathrm{~mm}$ bearings and 10W40 oil, the journal bearing losses can be reduced by $10 \%$ at $2000 \mathrm{rpm}$ and by approximately $30 \%$ at $4600 \mathrm{rpm}$ despite the significantly wider bearing shells.

\subsection{Conclusion}

The results show that small changes in the bearing geometry bear no significant impact on the friction losses in the journal bearings. However, the use of a low viscosity lubricant holds obvious advantages in regards to a reduction of these losses, despite the need of wider bearings to retain the bearing load capacity. In the presented example this combination of low viscosity lubricants with wider bearings revealed itself as optimal and proves approximately $10-30 \%$ decreased losses in comparison to the initial situation. Alternatively, if more complex in design, the increase in size of the journal bearing diameter and the therefore necessary larger journal diameter brings advantages also in regards to the $\mathrm{NVH}$ performance due to the increased stiffness of the crankshaft. Further measures for friction reduction like an on-demand oil supply could potentially also attain significant savings and be analysed through the presented model.

While this basic example of friction reduction in engines displays the efficiency of various measures, it is important to emphasise that the choice of the optimum lubricant affects the whole engine and the other major source of mechanical losses, namely the piston assembly, challenges with (partly) opposing requirements to the lubricant. In this sense, the optimum choice of the lubricant in terms of friction reduction shall only be taken under consideration of the complete system.

\section{Acknowledgment}

The authors would like to acknowledge several very interesting discussions on friction related topics and want to express their gratitude in particular to C. Forstner (MIBA Bearing Group), F. Novotny-Farkas (OMV Refining \& Marketing GmbH), A. Skiadas (K \& S Gleitlager GmbH) and O. Knaus (AVL List GmbH).

Further, the authors acknowledge the kind permission of the MIBA Bearing Group and the OMV Refining \& Marketing $\mathrm{GmbH}$ to publish the results and the financial support of the 'COMET K2 - Competence Centers for Excellent Technologies Program' of the Austrian Federal Ministry for Transport, Innovation and Technology (BMVIT), the Austrian Federal Ministry of Economy, Family and Youth (BMWFJ), the Austrian Research Promotion Agency (FFG), the Province of Styria and the Styrian Business Promotion Agency (SFG).

\section{Author details}

H. Allmaier, C. Priestner, D.E. Sander and F.M. Reich

Virtual Vehicle Competence Center, Austria 


\section{References}

[1] Allmaier, H., Priestner, C., Reich, F., Priebsch, H., Forstner, C. \& Novotny-Farkas, F. [2012a]. Predicting friction reliably and accurately in journal bearings - extending the simulation model to TEHD, Tribology International 58 (2013): 20-28.

[2] Allmaier, H., Priestner, C., Reich, F., Priebsch, H., Forstner, C. \& Novotny-Farkas, F. [2012b]. Predicting friction reliably and accurately in journal bearings - the importance of extensive oil-models, Tribology International 48: 93-101.

[3] Allmaier, H., Priestner, C., Six, C., Priebsch, H., Forstner, C. \& Novotny-Farkas, F. [2011]. Predicting friction reliably and accurately in journal bearings-a systematic validation of simulation results with experimental measurements, Tribology International 44(10): 1151-1160.

[4] Bair, S., Jarzynski, J. \& Winer, W. [2001]. The temperature, pressure and time dependence of lubricant viscosity, Tribology International 34(7): 461-468.

[5] Bukovnik, S., Offner, G., Caika, V., Priebsch, H. \& Bartz, W. [2007]. Thermo-elasto-hydrodynamic lubrication model for journal bearing including shear rate-dependent viscosity, Lubrication Science 19(4): 231-245.

[6] European Commission [2010]. Reducing $\mathrm{CO}_{2}$ emissions from passenger cars. URL: http://ec.europa.eu/clima/policies/transport/vehicles/cars/index_en.htm

[7] Fatu, A., Hajjam, M. \& Bonneau, D. [2006]. A new model of thermoelastohydrodynamic lubrication in dynamically loaded journal bearings, Journal of tribology 128: 85.

[8] Fontaras, G. \& Samaras, Z. [2010]. On the way to $130 \mathrm{~g} \mathrm{CO}_{2} / \mathrm{km}$-estimating the future characteristics of the average european passenger car, Energy Policy 38(4): 1826-1833.

[9] Greenwood, J. \& Williamson, J. [1966]. Contact of nominally flat surfaces, Proceedings of the Royal Society of London. Series A, Mathematical and Physical Sciences 295: 300-319.

[10] Hall, D. \& Moreland, J. [2001]. Fundamentals of rolling resistance, Rubber chemistry and technology 74: 525.

[11] Holmberg, K., Andersson, P. \& Erdemir, A. [2012]. Global energy consumption due to friction in passenger cars, Tribology International 47: 221-234.

[12] International Energy Agency [2006]. World energy outlook.

[13] International Energy Agency [2008]. Worldwide trends in energy use and efficiency key insights from IEA indicator analysis.

[14] Kim, B. \& Kim, K. [2001]. Thermo-elastohydrodynamic analysis of connecting rod bearing in internal combustion engine, Journal of tribology 123: 444.

[15] King, J. [2008]. The King review of low-carbon cars part I: the potential for reducing $\mathrm{CO}_{2}$ emissions from road transport, ISBN 978: 1-84532.

[16] Körfer, T., Kolbeck, A., Schnorbus, T., Busch, H., Kinoo, B., Henning, L. \& Severin, C. [2011]. Fuel consumption potential of the passenger car diesel engine after EURO 6, 32. Internationales Wiener Motorensymposium, VDI, Vienna, Austria, pp. 99-122.

[17] Krasser, J. [1996]. Thermoelastohydrodynamische Analyse dynamisch belasteter Radialgleitlager (Thermoelastohydrodynamic analysis of dynamically loaded journal bearings), $\mathrm{PhD}$ thesis, Graz University of Technology.

[18] Mittwollen, N. \& Glienicke, J. [1990]. Operating conditions of multi-lobe journal bearings under high thermal loads, Journal of Tribology 112: 330.

[19] Mufti, R. \& Priest, M. [2009]. Technique of simultaneous synchronized evaluation of the tribological components of an engine under realistic conditions, Proceedings 
of the Institution of Mechanical Engineers, Part D: Journal of Automobile Engineering 223(10): 1311-1325.

[20] Okamoto, Y., Kitahara, K., Ushijima, K., Aoyama, S., Xu, H. \& Jones, G. [2000]. A study for wear and fatigue on engine bearings by using EHL analysis, JSAE Review 21(2): 189-196.

[21] Patir, N. \& Cheng, H. [1978]. An average flow model for determining effects of three-dimensional roughness on partial hydrodynamic lubrication, ASME, Transactions, Journal of Lubrication Technology 100: 12-17.

[22] Patir, N. \& Cheng, H. [1979]. Application of average flow model to lubrication between rough sliding surfaces, ASME, Transactions, Journal of Lubrication Technology 101: 220-230.

[23] Priebsch, H. \& Krasser, J. [1997]. Simulation of the oil film behaviour in elastic engine bearings considering pressure and temperature dependent oil viscosity, Tribology Series 32: 651-659.

[24] Priestner, C., Allmaier, H., Priebsch, H. \& Forstner, C. [2012]. Refined simulation of friction power loss in crank shaft slider bearings considering wear in the mixed lubrication regime, Tribology International 46(1): 200-207.

[25] Priestner, C., Allmaier, H., Reich, F., Forstner, C. \& Novotny-Farkas, F. [2012]. Friction in highly loaded journal bearings, MTZ 4: 310-315.

[26] Smith, R. [2008]. Enabling technologies for demand management: Transport, Energy policy 36(12): 4444-4448.

[27] Tian, T. [2002]. Dynamic behaviours of piston rings and their practical impact. part 1: ring flutter and ring collapse and their effects on gas flow and oil transport, Proceedings of the Institution of Mechanical Engineers, Part J: Journal of Engineering Tribology 216(4): 209.

[28] Wang, Y., Zhang, C., Wang, Q. \& Lin, C. [2002]. A mixed-TEHD analysis and experiment of journal bearings under severe operating conditions, Tribology international 35(6): 395-407.

[29] Zhang, C. [2002]. TEHD behavior of non-newtonian dynamically loaded journal bearings in mixed lubrication for direct problem, Journal of Tribology 124: 178. 